This is the accepted version of the following article: Konstantoulea $\mathrm{K}$, Louros $\mathrm{N}$, Rousseau F, Schymkowitz J. Heterotypic interactions in amyloid function and disease. FEBS J. 2021 Jan 18. doi: 10.1111/febs.15719. Epub ahead of print. PMID: 33460517, Which has been published in final form at https://febs.onlinelibrary.wiley.com/doi/10.1111/febs.15719 


\title{
Heterotypic interactions in amyloid function and disease
}

\author{
Katerina Konstantoulea ${ }^{1,2 \#}$, Nikolaos Louros ${ }^{1,2 \#}$, Frederic Rousseau ${ }^{1,2 *}$ \& Joost Schymkowitz ${ }^{1,2 *}$ \\ ${ }^{1}$ VIB Center for Brain and Disease Research, Leuven, Belgium. \\ ${ }^{2}$ Switch Laboratory, Department of Cellular and Molecular Medicine, KU Leuven, Leuven, \\ Belgium. \\ \#equal contribution \\ *Corresponding authors: \\ Frederic Rousseau: Frederic.Rousseau@kuleuven.vib.be, +32 163725 70, Campus Gasthuisberg \\ O\&N 1, KU Leuven, Herestraat 49 Box 802 room 08.683, 3000 Leuven, Belgium
}

Joost Schymkowitz: Joost.Schymkowitz@kuleuven.vib.be, +32 $16 \quad 3725$ 70, Campus Gasthuisberg O\&N 1, KU Leuven, Herestraat 49 Box 802 room 08.683, 3000 Leuven, Belgium

\section{Running Title: Amyloid heterotypic interactions}

\begin{abstract}
Abbreviations
AA, Amyloid A amyloidosis; AApoAl, ApoAl amyloidosis; AApoAll, ApoAll amyloidosis; Acys, Acys Amyloidosis; AD, Alzheimer's disease; LC, immunoglobulin light chain; AL, Light chain amyloidosis; ALS, Amyotrophic lateral sclerosis; ApoAI, Apolipoprotein Al; ApoAll, Apolipoprotein All; ApoE, Apolipoprotein E; a-synuclein, alpha-synuclein; APRs, Aggregation-prone regions; ATXN, ataxin; $A \beta$, beta amyloid peptide; BRCA1, Breast cancer type 1 susceptibility protein; CA, Cerebral atherosclerosis; CJD, Creutzfeldt-Jakob disease; CMV, Cytomegalovirus; COPI, Coat protein I; cryo-EM, Cryogenic electron microscopy; CsgA, Major curli subunit; CsgB, Minor curli subunit; CsgF, Curli production assembly/transport component CsgF; CsgG, Curli production assembly/transport component CsgG; cysC, cystatin C; DLB, Dementia with Lewy Bodies; DRA, Dialysis related amyloidosis; EAAT, Excitatory amino acid transporter; EC, entorhinal cortex; FAC, Familial amyloid cardiomyopathy; FAD, Familial Alzheimer's disease; FAP, Familial amyloid polyneuropathy; FTD, Frontotemporal dementia; FTDP17, Frontotemporal dementia and parkinsonism linked to chromosome 17; FUS, RNA-binding protein FUS; GCls, Glial Cytoplasmic Inclusions; GFAP, Glial fibrillary acidic protein; GWAS, Genome-Wide Association Studies; HD, Huntington's disease; HIV, Human immunodeficiency virus; HSP70, Heat shock protein 70; HSP90, Heat shock protein 90; htt, Huntingtin; IAPP, Islet amyloid polypeptide; iPSCs, Induced pluripotent stem cells; LB, Lewy Bodies; MLKL, Mixed lineage kinase domain-like protein; MSA, multiple system atrophy; NLR, Nod-like receptor; PAP, prostatic acid phosphatase; PD, Parkinson's disease; PGRP-LC, Peptidoglycan-recognition protein LC; PGRP-LE, Peptidoglycan-recognition protein LE; PrP, Prion protein; PS1, Presenilin-1; PSP, Progressive Supranuclear Palsy; RBPs, RNA binding proteins; RHIMs, Rip homotypic interaction motifs; RIPK1, Receptor-interacting serine/threonineprotein kinase 1; RIPK3, Receptor-interacting serine/threonine-protein kinase 3; rpAD, rapidly progressive Alzheimer's disease; SAA, Serum amyloid A protein; SAD, sporadic Alzheimer's disease; SAP, Serum amyloid P; SCA1, Spinocerebellar ataxia type 1; SCA2, Spinocerebellar ataxia type 2; SCA3, Spinocerebellar ataxia type 3; SCA8, Spinocerebellar ataxia type 8; SCA10, Spinocerebellar ataxia type 10; SOD1, Superoxide dismutase 1; SSA, Senile systemic amyloidosis; Sup35, Eukaryotic peptide chain release factor GTP-binding subunit; T2D, type 2 diabetes; TDP43, TAR DNA-binding protein 43; Tia1, Nucleolysin TIA-1 isoform p40; TTR, Transthyretin; ZBP1, Z-DNA binding protein 1; ZP, Zona pellucida; $\beta 2 \mathrm{M}$, Beta-2 microglobulin
\end{abstract}

Keywords: heterotypic aggregation; co-aggregation; cross-seeding; amyloid co-deposition; functional amyloids; amyloidosis; prion transmissibility; aggregation-prone regions; selective 
vulnerability; supersaturated proteins; amyloid polymorphism; amyloid strains; phase transition; phase separation; sequence specificity;

Conflict of interest: The authors declare no conflict of interest. 


\begin{abstract}
Amyloid aggregation results from the self-assembly of identical aggregation-prone sequences into cross-beta-sheet structures. The process is best known for its association with a wide range of human pathologies but also as a functional mechanism in all kingdoms of life. Less well elucidated is the role of heterotypic interactions between amyloids and other proteins and macromolecules and how this contributes to disease. We here review current data with a focus on neurodegenerative amyloid-associated diseases. Evidence indicates that heterotypic interactions occur in a wide range of amyloid processes and that these interactions modify fundamental aspects of amyloid aggregation including seeding, aggregation rates and toxicity. More work is required to understand the mechanistic origin of these interactions, but current understanding suggests that both supersaturation and sequence-specific binding can contribute to heterotypic amyloid interactions. Further unravelling these mechanisms may help to answer outstanding questions in the field including the selective vulnerability of cells types and tissues and the stereotypical spreading patterns of amyloids in disease.
\end{abstract}




\section{Introduction}

Protein aggregation has been connected to more than 30 proteinopathies, ranging from neurodegeneration to Type 2 Diabetes (T2D) and systemic amyloidosis [1]. Despite the diversity in clinical presentation between these diseases and the heterogeneity of the affected tissues, common pathological hallmarks and principles unite them $[2,3]$ :

First, the tissues/organs that are most affected characterize each disease and dominate its symptoms. For example: Degeneration of motor neurons is at the heart of Amyotrophic Lateral Sclerosis (ALS)[4], resulting in the gradual weakening of the muscles, and in particular, the involuntary muscle groups. Degeneration of specific volumes of the brain stem causes Progressive Supranuclear Palsy (PSP)[5], leading to loss of balance, slowing of movement, difficulty moving the eyes, and dementia. Alzheimer's Disease (AD) is associated with degeneration in the hippocampus and cortex and hence leads to symptoms related to memory and behavior[6].

Second, amyloid deposits in the disease-defining tissue(s) are a unifying hallmark of the proteinopathies [7]. These amyloids are ordered proteins aggregates, characterized by the self-assembly of the proteins into cross-beta structured deposits. Together with the organ/tissue, the identity of the main proteins in the amyloid deposits defines the disease. Examples include TDP43 aggregates in ALS, tau aggregates in PSP, $\alpha$-synuclein aggregates in Parkinson's Disease (PD) and both $A \beta$ and tau aggregates in AD.

Third, unique stereo-specific spreading patterns are another characteristic of several of these diseases [2]. The aggregates appear first in a defining area and spread from there to functionally connected areas, notably in the brain, likely through synaptic connections. For example, $\alpha$-synuclein aggregates first appear in PD patients in the olfactory bulb and dorsal motor nucleus and spread from there to the substantia nigra and eventually to the neocortex[8]. This spread correlates to a progressive worsening of the clinical symptoms, of which the earliest often go unnoticed, such as a loss of the sense of smell in early PD.

These patterns of deposition and spreading have led to the proposal that the aggregates are the disease-causing agents and that their inherently cytotoxic properties disrupt cell- and tissue homeostasis [9]. Since the mechanisms through which aggregates achieve this remain poorly understood [10], the alternative view can however not be fully 
dismissed that aggregation in some cases may be a mere consequence of some other, not yet identified cause [11].

Protein aggregation is thus defined as a process of self-recognition and thus homotypic interactions, which is justified since the aggregates are typically strongly enriched in a single protein. However, protein deposits have long been known to contain a complexity of other components, both proteinaceous and other, and recently heterotypic interactions are increasingly being considered as potential modulators of both the aggregation itself and of its functional consequences. Heterotypic amyloid interactions might provide the mechanistic underpinnings of still insufficiently understood phenomena such as protein codeposition in amyloid plaques [12], polymorphism [13], transmissibility and prion-like behaviour [14]. Furthermore, heterotypic aggregate interactions could have beneficial functions in a cellular environment, such as sequestering toxic aggregates or mediating new functions. This apparent duality of heterotypic interactions makes them of great interest to further understand protein aggregation, and subsequently may also provide tools to manipulate the aggregation process to our advantage.

\section{Evidence of cross talk between pathological amyloidogenic proteins}

Although amyloid diseases are usually associated with one or two amyloid proteins such as mentioned above, there is growing evidence that amyloid pathology can co-occur in in the same tissue and this is often associated with more severe disease progression [15]. This co-occurrence may be an outcome of direct interactions between the aggregating proteins, such as co-aggregation or cross-seeding, or could be an indirect effect resulting from an overall decline in protein homeostasis in the affected tissues. Since the interplay of amyloid cross-interactions have extensively been reviewed recently [16-18], we limit this section to few notable examples (Fig. 1).

Alzheimer disease as such is a case in point as this neurodegenerative disease has been defined from the outset by the co-existence of amyloidogenic proteins in the same tissue. The main pathological hallmarks of $A D$ are the presence of both extracellular $A \beta$ aggregates and intracellular tau tangles [19]. Although the aggregation of $A \beta$ precedes the aggregation of tau by some time in the course of the disease [20], it is unclear if and how the 
aggregation is related to either, but there is evidence to suggest that the aggregation of one may directly affect the other, even if one is primarily intracellular (tau) and the other is primarily extracellular $(A \beta)$ [21]. It has been shown in vitro and in cells that pre-aggregated $A \beta$ can induce fibril-formation of tau [22]. Moreover, familial Alzheimer's disease (FAD) mutations in the amyloid precursor protein or presenilin-1 (PS1) can promote high levels of phosphorylated tau aggregates in 3D neuronal cell cultures [23]. Interestingly, upon inhibition of $A \beta$ production, both $A \beta$ and tau pathology was reduced in these models [23]. A similar observation was made in neurons derived from induced pluripotent stem cells (iPSCs) of AD patients [24]. Furthermore, evidence suggests that $A \beta$ aggregation enhances the aggregation of tau in triple-transgenic mouse models [25]. Studies in human brains of patients with AD have also shown that the presence of $A \beta$ pathology influences tau propagation [25].

It appears $A \beta$ aggregation may have other molecular links. Type 2 diabetes (T2D) is linked to the aggregation of the Islet amyloid polypeptide (IAPP), which causes loss of $\beta$-cells in the pancreatic islets of Langerhans. T2D has been associated with an increased risk of dementia, including AD and vascular dementia [26]. Although the specific mechanism behind this connection is not yet fully understood, several lines of evidence suggest that cross-talk between the protein aggregation that exists in both diseases may play a role. Indeed, crossseeding of $A \beta$ and IAPP has been shown in vitro, with IAPP increasing $A \beta$ aggregation [27]. Moreover, injection of A $\beta$ fibrils in IAPP transgenic mice successfully induced the aggregation of IAPP in the islet of Langerhans when compared to control groups [28]. Interestingly, IAPP has been found to co-deposit in amyloid plaques of $A D$ patients, even in absence of a diabetes diagnosis $[28,29]$. A potential explanation of the connection between A $\beta$ and IAPP may be found in their primary sequence, since both proteins share $50 \%$ sequence similarity, and have an even higher degree of similarity in the regions known to be important for self-aggregation $[30,31]$, suggesting this may play a role in cross-seeding and co-deposition in disease.

Aggregation of $\alpha$-synuclein into Lewy bodies (LB) has been connected to Parkinson's disease (PD). Although LB are the pathological hallmark of PD, $50 \%$ of $A D$ patients also exhibit $\alpha$-synuclein aggregates, which is associated to a more aggressive progress of the disease [3234]. NMR studies have shown that $A \beta$ peptides can interact with $\alpha$-synuclein, while kinetic aggregation studies suggest that the presence of $A \beta$ can accelerate the aggregation of $\alpha$ synuclein in vitro $[35,36]$. A similar observation was made in double transgenic mice expressing human $A \beta$ and $\alpha$-synuclein mimicking Lewy Body Alzheimer disease, with those 
mice having more $\alpha$-synuclein inclusions than the ones expressing only $\alpha$-synuclein[37]. In addition, crossing 3xTg-AD mice, that are expressing human APPsw, human P301L tau and $\mathrm{PS}^{\mathrm{M} 146 \mathrm{~V}}$ knock-in, which can develop plaques and tangles, with transgenic mice bearing the a-synuclein A53T mutation, simulated DLB-AD successfully and resulted in a drastic increase in cognitive disfunction and amyloid pathology [38]. A-synuclein also enhanced aggregation of tau, and both proteins affect each other's aggregation [39]. Moreover, tau positive aggregates have been identified in transgenic mice bearing A53T $\alpha$-synuclein mutation. Furthermore, $\alpha$-synuclein inclusions were found in double transgenic mice bearing wild type $\alpha$-synuclein and P301L tau [39]. Co-expression of $\alpha$-synuclein and tau in different cell models also showed that those proteins colocalize and that tau affects the number and pattern of $\alpha$ synuclein aggregation [40].

The presence of more than one amyloidogenic proteins is also found in other proteinopathies, such as Huntington's disease (HD). HD is a neurodegenerative disease caused by a mutation in the huntingtin (htt) gene, resulting in a CAG nucleotide expansion [41]. Many studies have shown that HD coexists with $\operatorname{ALS}$ and $\operatorname{AD}[42,43]$. Indeed, increased aggregation of $\alpha$-synuclein, tau and TDP-43 has been connected to HD brains [44]. Moreover, $\alpha$-synuclein aggregates have been colocalized in htt aggregates both in human and mouse brains [45]. Tau pathology has also been connected to HD. In detail, tau aggregates have been found to partially colocalize with htt aggregates and also exist in early-onset HD patients, indicating that it is not caused by normal aging [46]. In addition, studies in cells and mouse models showed that mutant htt affects phosphorylation of Tau, a process connected to tau aggregation [47].

Finally, SCA2 is a neurological disease caused by mutation in the ATXN2 gene resulting in a CAG expansion [48]. Evidences from a SCA2 patient's brain showed the presence of TDP43 aggregates, similar to those seen in ALS. Although, SCA2 and TDP43 aggregates were not found to co-deposit, the connection of TDP43 to many polyQ diseases suggest that there is a possible mechanism behind this co-existence [49]. Similarly, the RNA-binding protein FUS have been localized to intracellular inclusions in human brains of SCA1,2 and 3 [50].

\section{Heterogeneity of amyloid deposits}


In addition to the co-occurrence of main pathology-driving proteins such as described above, there is also considerable additional heterogeneity in the deposits themselves, both in terms of the proteins found as well as in the other types of biological macromolecules (Fig. 2). Although the mechanism behind this co-deposition is not well understood, recent advances in mass spectrometry allows ever better elucidation of this complexity, in particular in terms of the protein components of those aggregates. For example, amyloid plaques, of which the main component is the $A \beta$ peptide, have been found to be composed of $a$ significant number of other proteins. Indeed, mass-spectrometry studies on amyloid plaques from $A D$ patient brains have revealed the number of plaque-resident proteins to range from 400 to $1000[51,52]$. Although the number of proteins identified in each study differed, likely due to the specific procedures followed or the tissues analyzed, there appears to be similarities in the proteins identified: Glial related proteins like GFAP, EAAT and vimentin have been found repeatedly to reside in amyloid plaques and potentially provide a link to gliosis, a well characterized feature of $A D[52,53]$. Extracellular matrix proteins like glypican, testican, and cystatin have also been found in amyloid plaques [51,52]. Moreover, proteins of the complement system, for example $\mathrm{C} 1 \mathrm{q}, \mathrm{C} 1 \mathrm{r}, \mathrm{C} 1 \mathrm{~s}$ and $\mathrm{C} 5-\mathrm{C} 9$ have been associated with $\mathrm{A} \beta$ aggregates, possibly as result of the activation of the complement system during the course of the disease [51]. Furthermore, proteins connected to a variety of cellular processes like actin organization, chaperones, membrane trafficking and degradation have also been connected to $A \beta$ deposits [51-53]. Synaptic proteins and synaptic vesicle proteins have also been found in amyloid plaques, comprising $15 \%$ of the proteins found in them [53]. Interestingly, comparison of amyloid plaques from patients with rapidly progressive $A D$ (rpAD) and sporadic AD (sAD) showed that rpAD plaques contain more neuronal and synaptic proteins and less astrocyte-related ones [54]. These lines of evidence suggest that a significant number of proteins can co-deposit with $A \beta$ aggregates and that plaque composition is in some way related to disease progression.

Neurofibrillary tangles, consisting mainly of tau aggregates have also been shown to contain many cellular factors. Colocalization studies have shown that filamin-A and myosin VI localize with tau tangles in AD and FTDP-17 [55]. Moreover, BRCA1, a DNA nuclear protein, has been found to mis-localize and deposit with tau in different tauopathies, possibly causing loss of function and reducing DNA repair [56]. Furthermore, incubating different aggregated species of tau with rat brain lysate revealed a distinct interaction pattern compared to 
monomeric tau [57], suggesting aggregate-specific interactions occur. Interestingly, interactions changed during the course of aggregation. Early interactions contained proteins connected to Coat Protein I components, which in late stage aggregates were decreased in abundance [57]. In contrast, during these later stages of aggregation, proteins connected to RNA, phosphorylation and microtubules were able to interact highly with tau fibrils [57]. Coimmunoprecipitation of tau from microsomes isolated from $A D$ and control brains showed that $42.9 \%$ of the proteins identified were only found in AD brains, with proteins involved in RNA translation having higher abundances [58]. In addition, proteomics analysis of neurofibrillary tangles isolated from AD brains identified around 542 proteins [59]. These proteins include chaperones (HSP70, HSP90), proteins of peroxiredoxin family, proteins with RNA recognition motifs, 14-3-3 proteins, etc [59]. Interestingly, a significant number of the identified interactors of phosphorylated tau (a hallmark of the pathological form) were also present in tau tangles [59]. In addition, some of the interactors found in tau tangles were in fact only identified to be present in some of the cases, indicating that variation in the interactome between patients may hold important information for disease progression [59].

Similar observations have been made for other protein deposits, for example in Lewy bodies (LB), which mainly consist of $\alpha$-synuclein, but also been shown to contain a number of different proteins. These proteins have been connected to extracellular matrix, signaling and apoptosis, cytoskeleton, inflammation, proteins synthesis or degradation [60]. Moreover, synaptic vesicle proteins have been associated with the formation of LB in DLB and Glial Cytoplasmic Inclusions (GCls) in multiple system atrophy (MSA) [61]. Htt inclusion bodies have been found to be enriched in ubiquitin in living cells [62]. Moreover, cell culture experiments showed that insoluble htt aggregates are enriched in protein quality control proteins while soluble htt oligomers have the ability to interact with more than 800 different proteins connected to different cellular pathways [63].

\section{Deciphering the role of brain heterogeneity in aggregation diseases}

Despite being widely expressed in the brain, amyloid-forming proteins seem to follow specific spatiotemporal patterns of self-propagation that do not always appear to match disease progression [64]. For example: In AD patients, amyloid plaques spread along different areas of the brain, while the regional pattern of neurofibrillary tangles better resembles the progression of clinical symptoms $[65,66]$. Recent work using iPSCs from patients harbouring 
an amyloid precursor protein mutation revealed a differentiated response to $A \beta$ and tau by individual neuronal cell types, suggesting that cell-autonomous factors partially mediate spatiotemporal patterns of selective regional vulnerability [67]. This is supported by a plethora of information focused on charting cellular susceptibility, as regions located in the outer layer of the entorhinal cortex, basal forebrain and hippocampus are exceptionally vulnerable in $A D$, while glial cells, cortical neurons and inner layers of EC are more resistant, respectively [68-73]. Analysis of neuron-specific GWAS expression profiles linked cellular vulnerability with genes involved in processes of axon plasticity, tau splicing and aging [74].

The prominent role of the proteome heterogeneity per cellular type cannot be ignored, although the basis of this apparent selective vulnerability is still largely unknown [64]. Reelin and SMI32-immunoreactive EC neurons show increased vulnerability in both transgenic mice and human AD patients [75]. The former is an extracellular protein involved in synaptic transmission pathways that are pivotal for synaptic plasticity, neuronal migration and dendritogenesis [76]. Reelin has been reported to directly influence $A \beta$ aggregation, by prolonging oligomer lifetime and delaying $A \beta$ fibrillation, while overexpression in transgenic mice has been shown to rescue memory recognition by delaying the formation of amyloid plaques [77]. Despite this and the fact that $A \beta$ oligomerisation has been linked to increased expression of Reelin, co-aggregation entrapment was found to diminish the levels of Reelin and is directly associated to advanced Braak stages in AD patients [78], while additional studies indicate that Reelin impairment also compromises functional down-regulation of tau phosphorylation [79]. In another direct example, tau and lysozyme share a common mechanism of induced ribosomal sequestration through co-aggregation which causes dysregulation of protein translation pathways [80, 81], while cross-interaction with RNA molecules has been shown to regulate prion aggregation $[82,83]$. In this line, selective vulnerability to $\alpha$-synuclein aggregation has been linked with mitochondrial dysfunction and chronic inflammation in PD [84-86]. Co-aggregation of multiple defective proteins is a hallmark behind selective motor neuron dysfunction in ALS, as reviewed by Gomes et al. and others [87-89].

Taken together, the above have led to the notion that the temporal instability of the cellular proteome composition can mediate selective vulnerability through direct heterotypic interactions between the (pre-)amyloid aggregates and specific proteins, potentially 
exacerbated by a general decline in protein homeostasis due to aging or external stress [90]. Direct interactions between differentially controlled proteins are also compatible with amyloid cross-talk [91], as well as with the amyloid strain hypothesis [92]. However, it still remains possible that other more generalised mechanisms, such as metal binding or widespread collapse of cellular proteostasis may also explain why specific cell types are more susceptible to toxic aggregates [93-96].

\section{Protein supersaturation profiles}

Perhaps what best ties together co-aggregation and selective vulnerability is the proposed role of the supersaturation, i.e. accumulation to levels beyond their intrinsic solubility of specific sub-proteomes, in driving additional protein components to collapse into aggregate deposits (Fig. 3) [97-101]. This hypothesis was first formulated in a bid to explain selective susceptibility of neuronal cells in neurodegenerative diseases [97]. An intricate balance between protein supersaturation, external stress and the inherent metastability of subcellular proteome contents against proteostatic quality control machinery of cells was suggested to modulate neuronal susceptibility [97]. Apart of obvious supersaturation levels for major amyloidogenic proteins [98], it was shown that many other proteins exceed their solubility thresholds and indeed are found in many deposits associated with the major aggregation-related diseases, such as AD, PD and HD [99]. Follow-up analysis of single-cell transcriptomics and subcellular proteomics data revealed an enrichment of supersaturated proteins related to synaptic function and mitochondrial metabolism, that showed a remarkable overlap to regional vulnerability patterns observed in AD, PD, FTD and ALS [100]. Differential analysis of transcriptional regulation in $A D$, compared to aging, revealed that certain supersaturated protein populations have an increased propensity for aggregation and strongly correspond to patterns of down-regulated gene expression, suggesting that this might be a controlling mechanism against neurodegeneration [101]. A breakdown of the protein content of ALS-related inclusion bodies indicated that co-aggregating proteins are either interaction partners of the major protein constituents (TDP43, SOD1, FUS), or display supersaturated expression levels and increased metastability towards aggregation, suggesting that progressive impairment of the proteostatic mechanisms can trigger their codeposition in motor neurons [102]. Recently, it was shown that protein supersaturation levels are not only linked to neurodegenerative disorders, as a similar metastable subproteomic 
population was shown to dictate the formation of inclusions in muscular proteinopathies [103].

\section{Heterologous biomolecular condensation}

The formation of membraneless cellular inclusions through phase separation has been interchangeably linked to promoting, as well as to disfavouring the development of proteinopathies. Major amyloidogenic proteins, including $\alpha$-synuclein, tau and ALS-related proteins form heterogeneous condensates through phase separation that can contain up to hundreds of proteins [104-106]. Two basic modes of action have been proposed for stress granule-induced toxicity which is associated to neurodegenerative disorders $[107,108]$. In the first mode, gradual conversion of dysregulated condensates towards fibrillar aggregates can drive the entrapment and accumulation of their additional components, which causes cellular depletion and subsequent loss of function. Given that important autophagy-related proteins are recruited for their disassembly and clearance and that the majority of condensate heterocomponents refers to RNA-binding molecules [107, 108], sequestration and loss of their function can critically impair vital cellular activities, such as translation and protein quality control [109]. On the other hand, stress granule formation has also been depicted as an intermediate metastable state towards the formation of pathological amyloid aggregates $[104,110,111]$. In an interesting change of perspective, however, Mathieu et al. recently pointed out that stress granules can actually utilise heterotypic interactions as a molecular crowding scheme to prevent homotypic association of amyloidogenic components, which is the driving force of liquid-to-solid phase transition [112]. This buffering heterotypic interplay, as the authors mention, is an intricate balance that can be tipped by a change in the relative concentrations of the granule constituents, pathological mutations or additional competitive heterotypic interactions [112].

\section{Is sequence specificity a determining factor in amyloid heterotypic interactions?}

Early experiments indicated that cross-aggregation is somehow related to the sequence similarity between seeding and co-aggregating proteins [113]. In a landmark study, sequence conservation between neighbouring Ig-like domains of large multi-modular proteins was shown to determine their co-aggregation potential, as detectable interactions were observed only between immunoglobulin domains with more than $70 \%$ sequence 
identity [114]. As a result, neighbouring domains retain exposed aggregation-blocking conserved residues as an evolutionary strategy to prevent lateral aggregation in multidomain, $\beta$-folded or $\beta$-solenoid proteins [115-120]. ESI-IMS-MS experiments revealed that variants of IAPP can co-aggregate and form hetero-oligomers in pairwise mixtures, yet remain incapable of cross-seeding each other, suggesting that these are two separated processes that do not necessarily co-occur [121]. Cross-seeding mechanisms have been highlighted for diseaserelated variants of several other amyloid-forming proteins. Differential kinetic analysis of heterologous seeding between five conserved immunoglobulin light chains revealed that acceleration or deceleration of the nucleation process of one protein by another relied heavily on the conformational properties of the nucleator [122]. Cross-seeding studies between $\alpha$ synuclein and single-position variants, namely A30P and A53T, indicated that the wild-type protein aggregated faster and formed morphologically distinct fibrils in the presence of either A30P or A53T preformed seeds, whereas no cross-seeding was detected between the two variants [123]. This morphological alteration can probably be tracked-down to the diverse structural layout of fibrils formed by single mutants such as in the case of E46K [124], A53T [125] and H50Q [126], compared to WT $\alpha$-synuclein [127]. Different structural polymorphs have also been identified for other amyloid disease variants, such as the Alzheimer $\beta$-peptide lowa (D23N) [128] and Osaka [129] mutants, as well as the IAPP S20G mutant [130], when compared to wild type $A \beta[131,132]$ and IAPP $[130,133]$ fibril structures, respectively. In contrast, species complementarity was disclosed by cryo-EM structures of pathological amyloids involved in systemic AA amyloidosis, despite an evident difference in the handedness of their fibril twist [134]. Sequence selectivity has also been related to the structural compatibility that affects transmissibility of prions, although the limits of this dependence have been hard to determine in past studies $[135,136]$.

Whereas protein folding is determined by the cooperative formation of tertiary interactions, protein aggregation is determined by local secondary structural propensity of short sequence segments, 5-15 residues in length [137-141]. These aggregation-prone regions (APRs) act as the kinetic drivers of protein aggregation due to their tendency to selfassociate into ordered intermolecular $\beta$-sheet arrangements $[2,142]$. In this conformation, APRs are stapled together in $\beta$-sheets through a network of backbone hydrogen bonds and pack laterally via tightly interdigitated sidechains forming stable structures, known as steric 
zippers [143-145]. While sequences with a strong $\beta$-propensity are compatible with the generalized backbone stacking of $\beta$-strands, the intricate inter-fitting of side chains directly correlates to sequence specificity. Atomic structures of APR segment homologs from major prion protein (PrP) highlighted that sequence specificity critically confers interspecies transmissibility barriers [146]. Rationally designed single-position APR variants can alter both the aggregation propensity and cytotoxicity of hIAPP [147, 148], with additional work supporting that sequence variants can disrupt self-association and suppress aggregation of other proteins $[149,150]$. Co-expression studies of unrelated aggregating peptides, sharing no sequence similarity, resulted to the formation of separate inclusion bodies in mammalian, as well as E. coli cells [151]. Heterotypic steric zipper interfaces between distant APRs within amyloid sequences were initially predicted to shape the core of full-length protein amyloid fibrils $[2,152-155]$. This has been validated by the recent burst of cryo-EM fibril structures $[125,127,132-134,156-158]$. Indeed, cryo-EM structures reveal that intramolecular heterotypic interactions mediate the formation of different amyloid polymorphs by shaping internal zipper interfaces of the fibril core or by controlling the lateral interactions between protofibrils $[159,160]$. Multiple interfaces have been reported even in the structural packing of single APRs $[161,162]$. The role of amino acid composition has also been indirectly expanded to regions flanking APRs in protein sequences. Our recent work has shown that single residues flanking APRs in protein sequences can act as gatekeepers that attenuate aggregation propensity [138, 163-166], whereas sequence stretches of high disorder can affect the transmissibility of functional prion APRs by modulating aggregation morphology [167].

The first structure of a sequence-dependent heterotypic amyloid assembly has recently been solved by solid state NMR, and concerns the RIPK1-RIPK3 necrosome signalling complex, i.e. a functional amyloid that was evolved to form a stable hetero-amyloid structure [168]. Such heterotypic amyloid interactions are compatible with the strain hypothesis, according to which, a protein can form morphologically distinct strains that follow the structural characteristics of the seeding molecule, a concept that holds true in cases of hetero-assembly $[13,169,170]$. Exactly this was recently shown for two fragments of the $A \beta$ peptide: the two peptides form hetero-amyloids, but the amyloid conformation of the one peptide was modified by the presence of the second through unfolded state interactions, showing that strain selection can be steered by proteins that do not become part of the final 
aggregates [171]. Another familiar example of sequence-related cross-interacting APRs involves $A \beta$ and IAPP, despite the fact that they are spatially and functionally unrelated proteins [31]. The former has been shown to promote unilateral nucleation of IAPP, albeit with a lower efficiency compared to homologous assembly, whereby these proteins harbour stretches sharing sequence homology [172]. Several additional proteins have been associated to templated amyloid cross-talk via sharing of common structural architectures [161, 173175], with the list expanding even to cases of functional amyloids [176-182]. Finally, crossseeding and heterotypic co-aggregation has also been demonstrated in cancer-associated aggregation pathologies, where mutant p53 causes sequence-dependent co-deposition of its homologs p63 and p73 by virtue of their similar APRs [183-185].

\section{Hetero-aggregation in functional amyloids}

Several examples have been documented by previous studies, elucidating that amyloid cross-talk can be involved in the development of important biological functions, with cases spanning form bacteria to humans. Biogenesis of curli amyloid fibres in bacteria requires the co-operative action of six proteins encoded by shared operons [186]. Two subunits, known as major ( $\mathrm{Csg} A$ ) and minor ( $\mathrm{Csg} B$ ) curli subunit co-aggregate together to from the main axis of the curli fibres that remain attached to the surface through a heterotypic complex formed by CsgB, CsgF and a secreting pore formed by CsgG [186-188]. Both subunits have been shown to self-assemble, however CsgB pre-formed aggregates are also important for

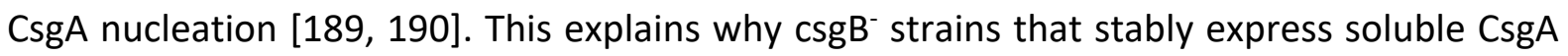
show remarkable interbacterial complementarity when growing in proximity to $\operatorname{csg} \mathrm{B}^{+} / \operatorname{csg}^{-}$ strains [191]. Computational studies indicate that this complementarity largely stems from the fact that CsgA and CsgB most likely adopt similar $\beta$-solenoid-like folds $[178,192,193]$. A similar mode of action has been proposed for FapC biofilm formation by $P$. fluorescens [194, 195], while amyloid hetero-interactions have also been proposed to contribute in the formation of aerial hyphae by chaplins [196].

The role of amyloids and their interplay with respect to the reproduction system has also been reviewed [197]. Early work highlighted that the protective egg coat of silkmoth and fish oocytes is in fact a natural protective amyloid structure $[198,199]$. Silkmoth chorion is composed by hetero-fibrils composed of a large number of proteins that are divided in two 
major families that share common central aggregation prone domains [200, 201]. Amyloid fibrils of fish egg coats, on the other hand, consist of heteromeric building blocks formed by proteins that share an evolutionarily conserved amyloidogenic domain with proteins of zona pellucida (ZP), the extracellular matrix that controls fertilisation and protects mammalian oocytes [202]. Follow-up studies later revealed that mouse ZP also exhibits typical amyloidlike properties [203], while structural analysis has shown that a conserved amyloidogenic interface is responsible for the heterotypic interaction of ZP proteins from fish to humans $[177,179,180]$. Impressively, the sperm acrosome which allows spermatozoa to penetrate the oocyte by interacting with ZP during fertilisation contains a proteinaceous matrix that is also composed of several amyloidogenic proteins such as cystatin-C, lysozyme and cystatinrelated epididymal spermatogenic protein [204]. Finally, semenogelin and prostatic acid phosphatase (PAP) form functional amyloid fibrils, found in seminal plasma, that immobilise and clear damaged sperm cells and bacteria by communicating with immune cells $[205,206]$, however also bind to HIV virions thus enhancing HIV transmission [207]. Similarly, A $\beta$ amyloid fibrils participate in hetero-interactions with receptors of HIV-1 enhancing viral attachment and infectivity $[208,209]$, although HIV-1 and Avibirnavirus have also been shown to utilize cross-reactive amyloids to increase their virulence [210, 211].

Hybrid amyloid constructs also play a pivotal role in necroptosis-associated signalling pathways. Formation of RIPK1-RIPK3 hetero-oligomeric signalling complexes, known as necrosomes, triggers phosphorylation of mixed lineage kinase domain-like protein (MLKL), which in turn mediates programmed necroptosis $[212,213]$. Interestingly, MLKL also selfassembles to form amyloid fibrils, however, no amyloid-related cross-talk between MLKL fibrils and necrosomes has yet been shown [214]. RIPK1-RIPK3 amyloid complex formation is controlled by conserved short Rip homotypic interaction motifs (RHIMs) [168]. Recently, a novel viral infection strategy has emerged indicating that the RHIM-associated necroptosis pathway can be repurposed by viral MLKL counterparts. Several proteins with high sequence similarity to the pseudokinase domain of MLKL were identified in poxvirus genomes and shown to circumvent phosphorylation of MLKL by competitive binding to necrosome amyloid complexes [215]. In this line, Sunde et al. recently showed that the murine cytomegalovirus (CMV) protein M45 contains a RHIM motif that directs its self-assembly into homo-oligomers. M45 oligomers can cross-interact with the RHIMs of RIPK1, RIPK3 and the Z-DNA binding 
protein 1 (ZBP1) to form heterotypic amyloid assemblies that block the necroptosis pathway in mice, thus explaining the ability of murine CMV to block necroptotic death [216]. The presence of RHIMs can be tracked down the evolutionary line, even to single cell organisms $[217,218]$. A similar aggregation motif has been identified in a Nod-like receptor (NLR) in $P$. anserine, which promotes its own amyloid-like self-assembly and participates in a similar amyloid-driven signalling pathway by catalysing the conversion of Het-s prions [219]. RHIMlike motifs found in peptidoglycan recognition proteins PGRP-LC and PGRP-LE also control signal transduction in $D$. melanogaster, while participating in hetero-aggregation with adaptor protein Imd to activate NF-kB signaling [220].

Prion transmissibility has been extensively linked to cross-seeding [14] and is considered a leading mechanism behind cross-species prion conversion [221, 222]. Formation of functional hetero-prions is often vital for important biological functions. Recent evidence revealed that Sup35 co-aggregates with prions deriving from the self-assembly of the known stress granule component protein Tia1, which self-propagates via a $\mathrm{Q} / \mathrm{N}$ rich domain. This hetero-amyloid assembly is a primary component of binding complexes that contribute to localised synthesis of tubulin by harbouring components of translation machinery [223]. Rnq1 initiates self-assembly of Sup35 through cross-talk interactions that are sensitive to singleresidue changes [224], as other critical residues moderate cross-species Sup35 transmission [225]. Previous work highlighted a similar mechanism to control strain-dependent seeding specificity and transmission barriers between mammalian prions [226]. This suggests that prion cross-infectivity is generally adjusted through a template-assisted mechanism that depends on strain-relevant structural conformation compatibility [169, 227]. Unilateral crossaggregation templating by alternative spliceoforms or naturally occurring glycosaminoglycans is an additional conformation-specific strategy used for the formation of functional amyloid in higher organisms [228, 229].

\section{Conclusions}

The after-effects of amyloid-like protein aggregation have long been directly associated to the adverse self-assembly of single aggregation-prone components. However, evidence is accumulating that identifying aggregation spreading patterns alone does not suffice in order to understand toxicity and selective vulnerability in proteinopathies. In this 
review, we discussed recent evidence that is gradually shifting interest towards the heterotypic interplay of amyloids between each other and with other proteins, as a framework to elucidate pathophysiological mechanisms of protein deposition diseases. More and more the realisation grows that pathological amyloidogenic proteins are involved in a dense network of heterotypic interactions that can either promote disease progression and severity, but can also have a beneficial effect by either reducing the aggregation propensity or toxicity of major amyloid constituents. This interconnectivity is further entangled when considering complementary studies indicating that even non-aggregating or diseaseunrelated proteins can modulate the morphology or aggregation rates of amyloidogenic proteins [230].

Following the rapid development of whole genome-expression and single-cell transcriptomics, a lot of effort has recently been put into identifying tissue-specific loci related to amyloid pathology. Disease-induced changes in expression profiles have been previously proposed to occur as a result of an indirect cellular response to protein aggregation. Co-aggregation has been extensively linked to promoting sequestration of cellular components with a role in translation, the depletion of which can provide context on the differences seen in transcriptional profiles between normal and disease brains. As prime example of this process, HD aggregates which are usually localized as nuclear inclusions promote sequestration of multiple transcription factors [231], while altered RNA metabolism is common in spinal motor neurons of ALS patients, as a result of the extensive co-deposition of RBPs [88]. Similarly, tau promotes co-aggregation of important RBPs involved in nuclear transport and chromatin remodeling [232], whereas single-cell proteomic profiling has shown that cerebral atherosclerosis is consistent with reduced synaptic signaling, RNA splicing and increased oligodendrocyte markers that associate to AD [233]. More evidence is required in order to determine if protein components of these pathways contribute to disease as innocent bystanders or as active modulators of co-aggregation. Nevertheless, it seems that the role of heterotypic interactions in this process can no longer remain unnoticed, as amyloids are constantly reported to trap vital proteins involved in diverse, yet pivotal pathways of cellular homeostasis, including inflammation, proteostatic control and autophagy among others [234].

In this overview we highlighted the emerging role of hetero-aggregation as an acquired structural strategy that complements amyloid polymorphism and thus facilitates 
prion-like properties, determines species-specific transmissibility barriers and controls crossnucleation induced by disease variants. A deeper look into the assembly mechanisms of major functional amyloids pinpointed that these proteins also contribute to the formation of heterocomplexes through surface-exposed APR interfaces of their native folds which share high structural complementarity. Nowadays, the wealth of structural information on amyloid fibrils and their polymorphic variants is constantly expanding, supporting the notion that sequence specificity is an important modulator of this structural compatibility. This hypothesis was also validated by experimental data on the first actual hetero-amyloid structure of RHIM-like motifs, building on years of work validating sequence specificity as a driving force behind prion inter-species infectibility and functional amyloid heterocomplex formation. However, as other mechanisms have also been recently reviewed in terms of supporting unspecific hetero-templating by amyloids through lateral or surface interactions [217], future work is required in order to determine the thresholds of sequence-specific mediated amyloid cross-talk, as well as to define its important in disease.

\section{Author Contributions}

All authors wrote and edited the manuscript.

\section{Acknowledgments}

This work was supported by the Flanders institute for Biotechnology (VIB); KU Leuven; the Fund for Scientific Research Flanders (FWO, project grants G0C2818N, G0C0320N, and G053420N); the Stichting Alzheimer Onderzoek (SAO-FRA 2019/0015, SAO-FRA 2020/0009, and SAO-FRA 2020/0013); the European Research Council under the European Union's Horizon 2020 Framework Programme ERC Grant Agreement (647458 MANGO); NL was funded by Fund for Scientific Research Flanders Post-doctoral Fellowship (12P0919N). 


\section{References}

1. Stefani, M. \& Dobson, C. M. (2003) Protein aggregation and aggregate toxicity: new insights into protein folding, misfolding diseases and biological evolution, $J$ Mol Med (Berl). 81, 678-99.

2. Eisenberg, D. \& Jucker, M. (2012) The amyloid state of proteins in human diseases, Cell. 148, 1188203.

3. Chiti, F. \& Dobson, C. M. (2017) Protein Misfolding, Amyloid Formation, and Human Disease: A Summary of Progress Over the Last Decade, Annu Rev Biochem. 86, 27-68.

4. Braak, H., Brettschneider, J., Ludolph, A. C., Lee, V. M., Trojanowski, J. Q. \& Del Tredici, K. (2013) Amyotrophic lateral sclerosis--a model of corticofugal axonal spread, Nature reviews Neurology. 9, 70814.

5. Goedert, M., Eisenberg, D. S. \& Crowther, R. A. (2017) Propagation of Tau Aggregates and Neurodegeneration, Annu Rev Neurosci. 40, 189-210.

6. Braak, H., Alafuzoff, I., Arzberger, T., Kretzschmar, H. \& Del Tredici, K. (2006) Staging of Alzheimer disease-associated neurofibrillary pathology using paraffin sections and immunocytochemistry, Acta Neuropathol. 112, 389-404.

7. Benson, M. D., Buxbaum, J. N., Eisenberg, D. S., Merlini, G., Saraiva, M. J. M., Sekijima, Y., Sipe, J. D. \& Westermark, P. (2018) Amyloid nomenclature 2018: recommendations by the International Society of Amyloidosis (ISA) nomenclature committee, Amyloid. 25, 215-219.

8. Braak, H., Del Tredici, K., Bratzke, H., Hamm-Clement, J., Sandmann-Keil, D. \& Rub, U. (2002) Staging of the intracerebral inclusion body pathology associated with idiopathic Parkinson's disease (preclinical and clinical stages), J Neurol. 249 Suppl 3, III/1-5.

9. Dobson, C. M., Knowles, T. P. J. \& Vendruscolo, M. (2019) The Amyloid Phenomenon and Its Significance in Biology and Medicine, Cold Spring Harbor perspectives in biology.

10. Gan, L., Cookson, M. R., Petrucelli, L. \& La Spada, A. R. (2018) Converging pathways in neurodegeneration, from genetics to mechanisms, Nat Neurosci. 21, 1300-1309.

11. Makin, S. (2018) The amyloid hypothesis on trial, Nature. 559, S4-S7.

12. Yan, J., Fu, X., Ge, F., Zhang, B., Yao, J., Zhang, H., Qian, J., Tomozawa, H., Naiki, H., Sawashita, J., Mori, M. \& Higuchi, K. (2007) Cross-seeding and cross-competition in mouse apolipoprotein A-II amyloid fibrils and protein A amyloid fibrils, Am J Pathol. 171, 172-80.

13. Surmacz-Chwedoruk, W., Nieznanska, H., Wojcik, S. \& Dzwolak, W. (2012) Cross-seeding of fibrils from two types of insulin induces new amyloid strains, Biochemistry. 51, 9460-9.

14. Soto, C. (2012) Transmissible proteins: expanding the prion heresy, Cell. 149, 968-77.

15. Park, K. W., Kim, H. S., Cheon, S. M., Cha, J. K., Kim, S. H. \& Kim, J. W. (2011) Dementia with Lewy Bodies versus Alzheimer's Disease and Parkinson's Disease Dementia: A Comparison of Cognitive Profiles, J Clin Neurol. 7, 19-24.

16. Biza, K. V., Nastou, K. C., Tsiolaki, P. L., Mastrokalou, C. V., Hamodrakas, S. J. \& Iconomidou, V. A. (2017) The amyloid interactome: Exploring protein aggregation, PLoS One. 12, e0173163.

17. Chaudhuri, P., Prajapati, K. P., Anand, B. G., Dubey, K. \& Kar, K. (2019) Amyloid cross-seeding raises new dimensions to understanding of amyloidogenesis mechanism, Ageing Res Rev. 56, 100937.

18. Luo, J., Warmlander, S. K., Graslund, A. \& Abrahams, J. P. (2016) Cross-interactions between the Alzheimer Disease Amyloid-beta Peptide and Other Amyloid Proteins: A Further Aspect of the Amyloid Cascade Hypothesis, J Biol Chem. 291, 16485-93.

19. Serrano-Pozo, A., Frosch, M. P., Masliah, E. \& Hyman, B. T. (2011) Neuropathological alterations in Alzheimer disease, Cold Spring Harb Perspect Med. 1, a006189.

20. Oddo, S., Caccamo, A., Kitazawa, M., Tseng, B. P. \& LaFerla, F. M. (2003) Amyloid deposition precedes tangle formation in a triple transgenic model of Alzheimer's disease, Neurobiol Aging. 24, 1063-70.

21. Jacobs, H. I. L., Hedden, T., Schultz, A. P., Sepulcre, J., Perea, R. D., Amariglio, R. E., Papp, K. V., Rentz, D. M., Sperling, R. A. \& Johnson, K. A. (2018) Structural tract alterations predict downstream tau accumulation in amyloid-positive older individuals, Nat Neurosci. 21, 424-431.

22. Vasconcelos, B., Stancu, I. C., Buist, A., Bird, M., Wang, P., Vanoosthuyse, A., Van Kolen, K., Verheyen, A., Kienlen-Campard, P., Octave, J. N., Baatsen, P., Moechars, D. \& Dewachter, I. (2016) Heterotypic seeding of Tau fibrillization by pre-aggregated Abeta provides potent seeds for prion-like seeding and propagation of Tau-pathology in vivo, Acta Neuropathol. 131, 549-69.

23. Choi, S. H., Kim, Y. H., Hebisch, M., Sliwinski, C., Lee, S., D'Avanzo, C., Chen, H., Hooli, B., Asselin, C., Muffat, J., Klee, J. B., Zhang, C., Wainger, B. J., Peitz, M., Kovacs, D. M., Woolf, C. J., Wagner, S. L., Tanzi, R. E. \& Kim, D. Y. (2014) A three-dimensional human neural cell culture model of Alzheimer's disease, Nature. 515, 274-8. 
24. Israel, M. A., Yuan, S. H., Bardy, C., Reyna, S. M., Mu, Y., Herrera, C., Hefferan, M. P., Van Gorp, S., Nazor, K. L., Boscolo, F. S., Carson, C. T., Laurent, L. C., Marsala, M., Gage, F. H., Remes, A. M., Koo, E. H. \& Goldstein, L. S. (2012) Probing sporadic and familial Alzheimer's disease using induced pluripotent stem cells, Nature. 482, 216-20.

25. Bennett, R. E., DeVos, S. L., Dujardin, S., Corjuc, B., Gor, R., Gonzalez, J., Roe, A. D., Frosch, M. P., Pitstick, R., Carlson, G. A. \& Hyman, B. T. (2017) Enhanced Tau Aggregation in the Presence of Amyloid beta, Am J Pathol. 187, 1601-1612.

26. Ninomiya, T. (2014) Diabetes mellitus and dementia, Curr Diab Rep. 14, 487.

27. Bharadwaj, P., Solomon, T., Sahoo, B. R., Ignasiak, K., Gaskin, S., Rowles, J., Verdile, G., Howard, M. J., Bond, C. S., Ramamoorthy, A., Martins, R. N. \& Newsholme, P. (2020) Amylin and beta amyloid proteins interact to form amorphous heterocomplexes with enhanced toxicity in neuronal cells, Sci Rep. 10, 10356.

28. Oskarsson, M. E., Paulsson, J. F., Schultz, S. W., Ingelsson, M., Westermark, P. \& Westermark, G. T. (2015) In vivo seeding and cross-seeding of localized amyloidosis: a molecular link between type 2 diabetes and Alzheimer disease, Am J Pathol. 185, 834-46.

29. Jackson, K., Barisone, G. A., Diaz, E., Jin, L. W., DeCarli, C. \& Despa, F. (2013) Amylin deposition in the brain: A second amyloid in Alzheimer disease?, Ann Neurol. 74, 517-26.

30. Andreetto, E., Yan, L. M., Caporale, A. \& Kapurniotu, A. (2011) Dissecting the role of single regions of an IAPP mimic and IAPP in inhibition of Abeta40 amyloid formation and cytotoxicity, Chembiochem. 12, 1313-22.

31. O'Nuallain, B., Williams, A. D., Westermark, P. \& Wetzel, R. (2004) Seeding specificity in amyloid growth induced by heterologous fibrils, J Biol Chem. 279, 17490-9.

32. Hamilton, R. L. (2000) Lewy bodies in Alzheimer's disease: a neuropathological review of 145 cases using alpha-synuclein immunohistochemistry, Brain Pathol. 10, 378-84.

33. Lippa, C. F., Fujiwara, H., Mann, D. M., Giasson, B., Baba, M., Schmidt, M. L., Nee, L. E., O'Connell, B., Pollen, D. A., St George-Hyslop, P., Ghetti, B., Nochlin, D., Bird, T. D., Cairns, N. J., Lee, V. M., Iwatsubo, T. \& Trojanowski, J. Q. (1998) Lewy bodies contain altered alpha-synuclein in brains of many familial Alzheimer's disease patients with mutations in presenilin and amyloid precursor protein genes, Am J Pathol. 153, 1365-70.

34. Arai, Y., Yamazaki, M., Mori, O., Muramatsu, H., Asano, G. \& Katayama, Y. (2001) Alpha-synucleinpositive structures in cases with sporadic Alzheimer's disease: morphology and its relationship to tau aggregation, Brain Res. 888, 287-296.

35. Mandal, P. K., Pettegrew, J. W., Masliah, E., Hamilton, R. L. \& Mandal, R. (2006) Interaction between Abeta peptide and alpha synuclein: molecular mechanisms in overlapping pathology of Alzheimer's and Parkinson's in dementia with Lewy body disease, Neurochem Res. 31, $1153-62$.

36. Koppen, J., Schulze, A., Machner, L., Wermann, M., Eichentopf, R., Guthardt, M., Hahnel, A., Klehm, J., Kriegeskorte, M. C., Hartlage-Rubsamen, M., Morawski, M., von Horsten, S., Demuth, H. U., Rossner, S. \& Schilling, S. (2020) Amyloid-Beta Peptides Trigger Aggregation of Alpha-Synuclein In Vitro, Molecules. 25.

37. Masliah, E., Rockenstein, E., Veinbergs, I., Sagara, Y., Mallory, M., Hashimoto, M. \& Mucke, L. (2001) beta-amyloid peptides enhance alpha-synuclein accumulation and neuronal deficits in a transgenic mouse model linking Alzheimer's disease and Parkinson's disease, Proc Natl Acad Sci U S A. 98, 12245-50.

38. Clinton, L. K., Blurton-Jones, M., Myczek, K., Trojanowski, J. Q. \& LaFerla, F. M. (2010) Synergistic Interactions between Abeta, tau, and alpha-synuclein: acceleration of neuropathology and cognitive decline, J Neurosci. 30, 7281-9.

39. Giasson, B. I., Forman, M. S., Higuchi, M., Golbe, L. I., Graves, C. L., Kotzbauer, P. T., Trojanowski, J. Q. \& Lee, V. M. (2003) Initiation and synergistic fibrillization of tau and alpha-synuclein, Science. 300, 636-40.

40. Badiola, N., de Oliveira, R. M., Herrera, F., Guardia-Laguarta, C., Goncalves, S. A., Pera, M., Suarez-Calvet, M., Clarimon, J., Outeiro, T. F. \& Lleo, A. (2011) Tau enhances alpha-synuclein aggregation and toxicity in cellular models of synucleinopathy, PLoS One. 6, e26609.

41. McColgan, P. \& Tabrizi, S. J. (2018) Huntington's disease: a clinical review, Eur J Neurol. 25, 2434.

42. Tada, M., Coon, E. A., Osmand, A. P., Kirby, P. A., Martin, W., Wieler, M., Shiga, A., Shirasaki, H., Tada, M., Makifuchi, T., Yamada, M., Kakita, A., Nishizawa, M., Takahashi, H. \& Paulson, H. L. (2012) Coexistence of Huntington's disease and amyotrophic lateral sclerosis: a clinicopathologic study, Acta Neuropathol. 124, 749-60. 
43. Davis, M. Y., Keene, C. D., Jayadev, S. \& Bird, T. (2014) The co-occurrence of Alzheimer's disease and Huntington's disease: a neuropathological study of 15 elderly Huntington's disease subjects, $J$ Huntingtons Dis. 3, 209-17.

44. St-Amour, I., Turgeon, A., Goupil, C., Planel, E. \& Hebert, S. S. (2018) Co-occurrence of mixed proteinopathies in late-stage Huntington's disease, Acta Neuropathol. 135, 249-265.

45. Charles, V., Mezey, E., Reddy, P. H., Dehejia, A., Young, T. A., Polymeropoulos, M. H., Brownstein, M. J. \& Tagle, D. A. (2000) Alpha-synuclein immunoreactivity of huntingtin polyglutamine aggregates in striatum and cortex of Huntington's disease patients and transgenic mouse models, Neurosci Lett. 289, 29-32.

46. Vuono, R., Winder-Rhodes, S., de Silva, R., Cisbani, G., Drouin-Ouellet, J., Network, R. I. o. t. E. H. s. D., Spillantini, M. G., Cicchetti, F. \& Barker, R. A. (2015) The role of tau in the pathological process and clinical expression of Huntington's disease, Brain. 138, 1907-18.

47. Blum, D., Herrera, F., Francelle, L., Mendes, T., Basquin, M., Obriot, H., Demeyer, D., Sergeant, N., Gerhardt, E., Brouillet, E., Buee, L. \& Outeiro, T. F. (2015) Mutant huntingtin alters Tau phosphorylation and subcellular distribution, Hum Mol Genet. 24, 76-85.

48. Klockgether, T., Mariotti, C. \& Paulson, H. L. (2019) Spinocerebellar ataxia, Nat Rev Dis Primers. $5,24$.

49. Toyoshima, Y., Tanaka, H., Shimohata, M., Kimura, K., Morita, T., Kakita, A. \& Takahashi, H. (2011) Spinocerebellar ataxia type 2 (SCA2) is associated with TDP-43 pathology, Acta Neuropathol. 122, 375-8.

50. Doi, H., Koyano, S., Suzuki, Y., Nukina, N. \& Kuroiwa, Y. (2010) The RNA-binding protein FUS/TLS is a common aggregate-interacting protein in polyglutamine diseases, Neurosci Res. 66, 131-3.

51. Xiong, F., Ge, W. \& Ma, C. (2019) Quantitative proteomics reveals distinct composition of amyloid plaques in Alzheimer's disease, Alzheimers Dement. 15, 429-440.

52. Liao, L., Cheng, D., Wang, J., Duong, D. M., Losik, T. G., Gearing, M., Rees, H. D., Lah, J. J., Levey, A. I. \& Peng, J. (2004) Proteomic characterization of postmortem amyloid plaques isolated by laser capture microdissection, J Biol Chem. 279, 37061-8.

53. Hadley, K. C., Rakhit, R., Guo, H., Sun, Y., Jonkman, J. E., McLaurin, J., Hazrati, L. N., Emili, A. \& Chakrabartty, A. (2015) Determining composition of micron-scale protein deposits in neurodegenerative disease by spatially targeted optical microproteomics, Elife. 4.

54. Drummond, E., Nayak, S., Faustin, A., Pires, G., Hickman, R. A., Askenazi, M., Cohen, M., Haldiman, T., Kim, C., Han, X., Shao, Y., Safar, J. G., Ueberheide, B. \& Wisniewski, T. (2017) Proteomic differences in amyloid plaques in rapidly progressive and sporadic Alzheimer's disease, Acta Neuropathol. 133, 933-954.

55. Feuillette, S., Deramecourt, V., Laquerriere, A., Duyckaerts, C., Delisle, M. B., Maurage, C. A., Blum, D., Buee, L., Frebourg, T., Campion, D. \& Lecourtois, M. (2010) Filamin-A and Myosin VI colocalize with fibrillary Tau protein in Alzheimer's disease and FTDP-17 brains, Brain Res. 1345, $182-$ 9.

56. Kurihara, M., Mano, T., Saito, Y., Murayama, S., Toda, T. \& Iwata, A. (2019) Colocalization of BRCA1 with Tau Aggregates in Human Tauopathies, Brain Sci. 10.

57. Ferrari, L., Stucchi, R., Konstantoulea, K., van de Kamp, G., Kos, R., Geerts, W. J. C., van Bezouwen, L. S., Forster, F. G., Altelaar, M., Hoogenraad, C. C. \& Rudiger, S. G. D. (2020) Arginine pi-stacking drives binding to fibrils of the Alzheimer protein Tau, Nat Commun. 11, 571.

58. Meier, S., Bell, M., Lyons, D. N., Ingram, A., Chen, J., Gensel, J. C., Zhu, H., Nelson, P. T. \& Abisambra, J. F. (2015) Identification of Novel Tau Interactions with Endoplasmic Reticulum Proteins in Alzheimer's Disease Brain, J Alzheimers Dis. 48, 687-702.

59. Drummond, E., Pires, G., MacMurray, C., Askenazi, M., Nayak, S., Bourdon, M., Safar, J., Ueberheide, B. \& Wisniewski, T. (2020) Phosphorylated tau interactome in the human Alzheimer's disease brain, Brain. 143, 2803-2817.

60. Leverenz, J. B., Umar, I., Wang, Q., Montine, T. J., McMillan, P. J., Tsuang, D. W., Jin, J., Pan, C., Shin, J., Zhu, D. \& Zhang, J. (2007) Proteomic identification of novel proteins in cortical lewy bodies, Brain Pathol. 17, 139-45.

61. McCormack, A., Keating, D. J., Chegeni, N., Colella, A., Wang, J. J. \& Chataway, T. (2019) Abundance of Synaptic Vesicle-Related Proteins in Alpha-Synuclein-Containing Protein Inclusions Suggests a Targeted Formation Mechanism, Neurotox Res. 35, 883-897.

62. Juenemann, K., Jansen, A. H. P., van Riel, L., Merkx, R., Mulder, M. P. C., An, H., Statsyuk, A., Kirstein, J., Ovaa, H. \& Reits, E. A. (2018) Dynamic recruitment of ubiquitin to mutant huntingtin inclusion bodies, Sci Rep. 8, 1405. 
63. Kim, Y. E., Hosp, F., Frottin, F., Ge, H., Mann, M., Hayer-Hartl, M. \& Hartl, F. U. (2016) Soluble Oligomers of PolyQ-Expanded Huntingtin Target a Multiplicity of Key Cellular Factors, Mol Cell. 63, 951-64.

64. Fu, H., Hardy, J. \& Duff, K. E. (2018) Selective vulnerability in neurodegenerative diseases, Nat Neurosci. 21, 1350-1358.

65. Bussiere, T., Giannakopoulos, P., Bouras, C., Perl, D. P., Morrison, J. H. \& Hof, P. R. (2003) Progressive degeneration of nonphosphorylated neurofilament protein-enriched pyramidal neurons predicts cognitive impairment in Alzheimer's disease: stereologic analysis of prefrontal cortex area $9, J$ Comp Neurol. 463, 281-302.

66. Sepulcre, J., Grothe, M. J., Sabuncu, M., Chhatwal, J., Schultz, A. P., Hanseeuw, B., El Fakhri, G., Sperling, R. \& Johnson, K. A. (2017) Hierarchical Organization of Tau and Amyloid Deposits in the Cerebral Cortex, JAMA Neurol. 74, 813-820.

67. Muratore, C. R., Zhou, C., Liao, M., Fernandez, M. A., Taylor, W. M., Lagomarsino, V. N., Pearse, R. V., 2nd, Rice, H. C., Negri, J. M., He, A., Srikanth, P., Callahan, D. G., Shin, T., Zhou, M., Bennett, D. A., Noggle, S., Love, J. C., Selkoe, D. J. \& Young-Pearse, T. L. (2017) Cell-type Dependent Alzheimer's Disease Phenotypes: Probing the Biology of Selective Neuronal Vulnerability, Stem Cell Reports. 9, 1868-1884.

68. Cembrowski, M. S., Wang, L., Sugino, K., Shields, B. C. \& Spruston, N. (2016) Hipposeq: a comprehensive RNA-seq database of gene expression in hippocampal principal neurons, Elife. 5, e14997.

69. Morrison, J. H. \& Hof, P. R. (2002) Selective vulnerability of corticocortical and hippocampal circuits in aging and Alzheimer's disease, Prog Brain Res. 136, 467-86.

70. Small, S. A., Kent, K., Pierce, A., Leung, C., Kang, M. S., Okada, H., Honig, L., Vonsattel, J. P. \& $\mathrm{Kim}, \mathrm{T}$. W. (2005) Model-guided microarray implicates the retromer complex in Alzheimer's disease, Ann Neurol. 58, 909-19.

71. Stranahan, A. M. \& Mattson, M. P. (2010) Selective vulnerability of neurons in layer II of the entorhinal cortex during aging and Alzheimer's disease, Neural Plast. 2010, 108190.

72. Whitehouse, P. J., Price, D. L., Struble, R. G., Clark, A. W., Coyle, J. T. \& Delon, M. R. (1982) Alzheimer's disease and senile dementia: loss of neurons in the basal forebrain, Science. 215, 1237-9. 73. Jonson, M., Nystrom, S., Sandberg, A., Carlback, M., Michno, W., Hanrieder, J., Starkenberg, A., Nilsson, K. P. R., Thor, S. \& Hammarstrom, P. (2018) Aggregated Abeta1-42 Is Selectively Toxic for Neurons, Whereas Glial Cells Produce Mature Fibrils with Low Toxicity in Drosophila, Cell Chem Biol. 25, 595-610 e5.

74. Roussarie, J. P., Yao, V., Rodriguez-Rodriguez, P., Oughtred, R., Rust, J., Plautz, Z., Kasturia, S., Albornoz, C., Wang, W., Schmidt, E. F., Dannenfelser, R., Tadych, A., Brichta, L., Barnea-Cramer, A., Heintz, N., Hof, P. R., Heiman, M., Dolinski, K., Flajolet, M., Troyanskaya, O. G. \& Greengard, P. (2020) Selective Neuronal Vulnerability in Alzheimer's Disease: A Network-Based Analysis, Neuron. 107, 821835 e12.

75. Chin, J., Massaro, C. M., Palop, J. J., Thwin, M. T., Yu, G. Q., Bien-Ly, N., Bender, A. \& Mucke, L. (2007) Reelin depletion in the entorhinal cortex of human amyloid precursor protein transgenic mice and humans with Alzheimer's disease, $J$ Neurosci. 27, 2727-33.

76. Yu, N. N., Tan, M. S., Yu, J. T., Xie, A. M. \& Tan, L. (2016) The Role of Reelin Signaling in Alzheimer's Disease, Mol Neurobiol. 53, 5692-5700.

77. Pujadas, L., Rossi, D., Andres, R., Teixeira, C. M., Serra-Vidal, B., Parcerisas, A., Maldonado, R., Giralt, E., Carulla, N. \& Soriano, E. (2014) Reelin delays amyloid-beta fibril formation and rescues cognitive deficits in a model of Alzheimer's disease, Nature Communications. $\mathbf{5}$.

78. Cuchillo-lbanez, I., Mata-Balaguer, T., Balmaceda, V., Arranz, J. J., Nimpf, J. \& Saez-Valero, J. (2016) The beta-amyloid peptide compromises Reelin signaling in Alzheimer's disease, Sci Rep. 6, 31646.

79. Cuchillo-lbanez, I., Balmaceda, V., Botella-Lopez, A., Rabano, A., Avila, J. \& Saez-Valero, J. (2013) Beta-amyloid impairs reelin signaling, PLoS One. 8, e72297.

80. Banerjee, S., Ferdosh, S., Ghosh, A. N. \& Barat, C. (2020) Tau protein- induced sequestration of the eukaryotic ribosome: Implications in neurodegenerative disease, Sci Rep. 10, 5225.

81. Pathak, B. K., Mondal, S., Banerjee, S., Ghosh, A. N. \& Barat, C. (2017) Sequestration of Ribosome during Protein Aggregate Formation: Contribution of ribosomal RNA, Sci Rep. 7, 42017.

82. Kovachev, P. S., Gomes, M. P. B., Cordeiro, Y., Ferreira, N. C., Valadao, L. P. F., Ascari, L. M., Rangel, L. P., Silva, J. L. \& Sanyal, S. (2019) RNA modulates aggregation of the recombinant mammalian prion protein by direct interaction, Sci Rep. 9, 12406.

83. Pang, Y., Kovachev, P. \& Sanyal, S. (2020) Ribosomal RNA Modulates Aggregation of the Podospora Prion Protein HET-s, Int J Mol Sci. 21. 
84. Azizi, S. A. \& Azizi, S. A. (2018) Synucleinopathies in neurodegenerative diseases: Accomplices, an inside job and selective vulnerability, Neurosci Lett. 672, 150-152.

85. Horvath, I., lashchishyn, I. A., Moskalenko, R. A., Wang, C., Warmlander, S., Wallin, C., Graslund, A., Kovacs, G. G. \& Morozova-Roche, L. A. (2018) Co-aggregation of pro-inflammatory S100A9 with alpha-synuclein in Parkinson's disease: ex vivo and in vitro studies, $J$ Neuroinflammation. 15, 172.

86. Ryan, B. J., Hoek, S., Fon, E. A. \& Wade-Martins, R. (2015) Mitochondrial dysfunction and mitophagy in Parkinson's: from familial to sporadic disease, Trends Biochem Sci. 40, 200-10.

87. Droppelmann, C. A., Campos-Melo, D., Moszczynski, A. J., Amzil, H. \& Strong, M. J. (2019) TDP43 aggregation inside micronuclei reveals a potential mechanism for protein inclusion formation in ALS, Sci Rep. 9, 19928.

88. Keller, B. A., Volkening, K., Droppelmann, C. A., Ang, L. C., Rademakers, R. \& Strong, M. J. (2012) Co-aggregation of RNA binding proteins in ALS spinal motor neurons: evidence of a common pathogenic mechanism, Acta Neuropathol. 124, 733-47.

89. Leal, S. S. \& Gomes, C. M. (2015) Calcium dysregulation links ALS defective proteins and motor neuron selective vulnerability, Front Cell Neurosci. 9, 225.

90. Hardy, J. (2016) Catastrophic cliffs: a partial suggestion for selective vulnerability in neurodegenerative diseases, Biochem Soc Trans. 44, 659-61.

91. Guo, J. L., Covell, D. J., Daniels, J. P., Iba, M., Stieber, A., Zhang, B., Riddle, D. M., Kwong, L. K., Xu, Y., Trojanowski, J. Q. \& Lee, V. M. (2013) Distinct alpha-synuclein strains differentially promote tau inclusions in neurons, Cell. 154, 103-17.

92. Aguzzi, A., Heikenwalder, M. \& Polymenidou, M. (2007) Insights into prion strains and neurotoxicity, Nat Rev Mol Cell Biol. 8, 552-61.

93. Jackson, W. S. (2014) Selective vulnerability to neurodegenerative disease: the curious case of Prion Protein, Dis Model Mech. 7, 21-9.

94. Kaushik, S. \& Cuervo, A. M. (2015) Proteostasis and aging, Nat Med. 21, 1406-15.

95. Labbadia, J. \& Morimoto, R. I. (2015) The biology of proteostasis in aging and disease, Annu Rev Biochem. 84, 435-64.

96. Chung, C. G., Lee, H. \& Lee, S. B. (2018) Mechanisms of protein toxicity in neurodegenerative diseases, Cell Mol Life Sci. 75, 3159-3180.

97. Ciryam, P., Kundra, R., Morimoto, R. I., Dobson, C. M. \& Vendruscolo, M. (2015) Supersaturation is a major driving force for protein aggregation in neurodegenerative diseases, Trends Pharmacol Sci. 36, 72-7.

98. Hardy, J. (2005) Expression of normal sequence pathogenic proteins for neurodegenerative disease contributes to disease risk: 'permissive templating' as a general mechanism underlying neurodegeneration, Biochem Soc Trans. 33, 578-81.

99. Ciryam, P., Tartaglia, G. G., Morimoto, R. I., Dobson, C. M. \& Vendruscolo, M. (2013) Widespread aggregation and neurodegenerative diseases are associated with supersaturated proteins, Cell reports. 5, 781-90.

100. Freer, R., Sormanni, P., Ciryam, P., Rammner, B., Rizzoli, S. O., Dobson, C. M. \& Vendruscolo, M. (2019) Supersaturated proteins are enriched at synapses and underlie cell and tissue vulnerability in Alzheimer's disease, Heliyon. 5, e02589.

101. Ciryam, P., Kundra, R., Freer, R., Morimoto, R. I., Dobson, C. M. \& Vendruscolo, M. (2016) A transcriptional signature of Alzheimer's disease is associated with a metastable subproteome at risk for aggregation, Proc Natl Acad Sci U S A. 113, 4753-8.

102. Ciryam, P., Lambert-Smith, I. A., Bean, D. M., Freer, R., Cid, F., Tartaglia, G. G., Saunders, D. N., Wilson, M. R., Oliver, S. G., Morimoto, R. I., Dobson, C. M., Vendruscolo, M., Favrin, G. \& Yerbury, J. J. (2017) Spinal motor neuron protein supersaturation patterns are associated with inclusion body formation in ALS, Proc Natl Acad Sci U S A. 114, E3935-E3943.

103. Ciryam, P., Antalek, M., Cid, F., Tartaglia, G. G., Dobson, C. M., Guettsches, A. K., Eggers, B., Vorgerd, M., Marcus, K., Kley, R. A., Morimoto, R. I., Vendruscolo, M. \& Weihl, C. C. (2019) A metastable subproteome underlies inclusion formation in muscle proteinopathies, Acta Neuropathol Commun. 7, 197.

104. Ray, S., Singh, N., Kumar, R., Patel, K., Pandey, S., Datta, D., Mahato, J., Panigrahi, R., Navalkar, A., Mehra, S., Gadhe, L., Chatterjee, D., Sawner, A. S., Maiti, S., Bhatia, S., Gerez, J. A., Chowdhury, A., Kumar, A., Padinhateeri, R., Riek, R., Krishnamoorthy, G. \& Maji, S. K. (2020) alpha-Synuclein aggregation nucleates through liquid-liquid phase separation, Nat Chem. 12, 705-716.

105. Vanderweyde, T., Apicco, D. J., Youmans-Kidder, K., Ash, P. E. A., Cook, C., Lummertz da Rocha, E., Jansen-West, K., Frame, A. A., Citro, A., Leszyk, J. D., Ivanov, P., Abisambra, J. F., Steffen, M., Li, H., Petrucelli, L. \& Wolozin, B. (2016) Interaction of tau with the RNA-Binding Protein TIA1 Regulates tau Pathophysiology and Toxicity, Cell Rep. 15, 1455-1466. 
106. St George-Hyslop, P., Lin, J. Q., Miyashita, A., Phillips, E. C., Qamar, S., Randle, S. J. \& Wang, G. (2018) The physiological and pathological biophysics of phase separation and gelation of RNA binding proteins in amyotrophic lateral sclerosis and fronto-temporal lobar degeneration, Brain Res. 1693, 11-23.

107. Wolozin, B. (2012) Regulated protein aggregation: stress granules and neurodegeneration, $\mathrm{Mol}$ Neurodegener. 7, 56.

108. Wolozin, B. \& Ivanov, P. (2019) Stress granules and neurodegeneration, Nat Rev Neurosci. 20, 649-666.

109. Olzscha, H., Schermann, S. M., Woerner, A. C., Pinkert, S., Hecht, M. H., Tartaglia, G. G., Vendruscolo, M., Hayer-Hartl, M., Hartl, F. U. \& Vabulas, R. M. (2011) Amyloid-like aggregates sequester numerous metastable proteins with essential cellular functions, Cell. 144, 67-78.

110. Brunello, C. A., Yan, X. \& Huttunen, H. J. (2016) Internalized Tau sensitizes cells to stress by promoting formation and stability of stress granules, Sci Rep. 6, 30498.

111. Gui, X., Luo, F., Li, Y., Zhou, H., Qin, Z., Liu, Z., Gu, J., Xie, M., Zhao, K., Dai, B., Shin, W. S., He, J., He, L., Jiang, L., Zhao, M., Sun, B., Li, X., Liu, C. \& Li, D. (2019) Structural basis for reversible amyloids of hnRNPA1 elucidates their role in stress granule assembly, Nat Commun. 10, 2006.

112. Mathieu, C., Pappu, R. V. \& Taylor, J. P. (2020) Beyond aggregation: Pathological phase transitions in neurodegenerative disease, Science. 370, 56-60.

113. Krebs, M. R., Morozova-Roche, L. A., Daniel, K., Robinson, C. V. \& Dobson, C. M. (2004) Observation of sequence specificity in the seeding of protein amyloid fibrils, Protein Sci. 13, 1933-8.

114. Wright, C. F., Teichmann, S. A., Clarke, J. \& Dobson, C. M. (2005) The importance of sequence diversity in the aggregation and evolution of proteins, Nature. 438, 878-81.

115. Steward, A., Adhya, S. \& Clarke, J. (2002) Sequence conservation in Ig-like domains: the role of highly conserved proline residues in the fibronectin type III superfamily, Journal of molecular biology. 318, 935-40.

116. Richardson, J. S. \& Richardson, D. C. (2002) Natural beta-sheet proteins use negative design to avoid edge-to-edge aggregation, Proc Natl Acad Sci U S A. 99, 2754-9.

117. Louros, N. N., Baltoumas, F. A., Hamodrakas, S. J. \& Iconomidou, V. A. (2016) A beta-solenoid model of the Pmel17 repeat domain: insights to the formation of functional amyloid fibrils, $J$ Comput Aided Mol Des. 30, 153-64.

118. Louros, N. N. \& Iconomidou, V. A. (2016) Identification of an amyloid fibril forming segment of human Pmel17 repeat domain (RPT domain), Biopolymers. 106, 133-9.

119. Lazo, N. D. \& Downing, D. T. (1999) Fibril formation by amyloid-beta proteins may involve betahelical protofibrils, J Pept Res. 53, 633-40.

120. Kajava, A. V. \& Steven, A. C. (2006) Beta-rolls, beta-helices, and other beta-solenoid proteins, Adv Protein Chem. 73, 55-96.

121. Young, L. M., Tu, L. H., Raleigh, D. P., Ashcroft, A. E. \& Radford, S. E. (2017) Understanding copolymerization in amyloid formation by direct observation of mixed oligomers, Chem Sci. 8, 5030-5040. 122. Blancas-Mejia, L. M. \& Ramirez-Alvarado, M. (2016) Recruitment of Light Chains by Homologous and Heterologous Fibrils Shows Distinctive Kinetic and Conformational Specificity, Biochemistry. 55, 2967-78.

123. Sidhu, A., Segers-Nolten, I. \& Subramaniam, V. (2016) Conformational Compatibility Is Essential for Heterologous Aggregation of alpha-Synuclein, ACS Chem Neurosci. 7, 719-27.

124. Boyer, D. R., Li, B., Sun, C., Fan, W., Zhou, K., Hughes, M. P., Sawaya, M. R., Jiang, L. \& Eisenberg, D. S. (2020) The alpha-synuclein hereditary mutation E46K unlocks a more stable, pathogenic fibril structure, Proc Natl Acad Sci U S A. 117, 3592-3602.

125. Sun, Y., Hou, S., Zhao, K., Long, H., Liu, Z., Gao, J., Zhang, Y., Su, X. D., Li, D. \& Liu, C. (2020) Cryo-EM structure of full-length alpha-synuclein amyloid fibril with Parkinson's disease familial A53T mutation, Cell Res. 30, 360-362.

126. Boyer, D. R., Li, B., Sun, C., Fan, W., Sawaya, M. R., Jiang, L. \& Eisenberg, D. S. (2019) Structures of fibrils formed by alpha-synuclein hereditary disease mutant $\mathrm{H} 50 \mathrm{Q}$ reveal new polymorphs, Nat Struct Mol Biol. 26, 1044-1052.

127. Li, B., Ge, P., Murray, K. A., Sheth, P., Zhang, M., Nair, G., Sawaya, M. R., Shin, W. S., Boyer, D. R., Ye, S., Eisenberg, D. S., Zhou, Z. H. \& Jiang, L. (2018) Cryo-EM of full-length alpha-synuclein reveals fibril polymorphs with a common structural kernel, Nat Commun. 9, 3609.

128. Sgourakis, N. G., Yau, W. M. \& Qiang, W. (2015) Modeling an in-register, parallel "iowa" abeta fibril structure using solid-state NMR data from labeled samples with rosetta, Structure. 23, 216-227.

129. Schutz, A. K., Vagt, T., Huber, M., Ovchinnikova, O. Y., Cadalbert, R., Wall, J., Guntert, P., Bockmann, A., Glockshuber, R. \& Meier, B. H. (2015) Atomic-resolution three-dimensional structure of amyloid beta fibrils bearing the Osaka mutation, Angew Chem Int Ed Engl. 54, 331-5. 
130. Gallardo, R., ladanza, M. G., Xu, Y., Heath, G. R., Foster, R., Radford, S. E. \& Ranson, N. A. (2020) Fibril structures of diabetes-related amylin variants reveal a basis for surface-templated assembly, Nature Structural \& Molecular Biology.

131. Gremer, L., Scholzel, D., Schenk, C., Reinartz, E., Labahn, J., Ravelli, R. B. G., Tusche, M., Lopez-Iglesias, C., Hoyer, W., Heise, H., Willbold, D. \& Schroder, G. F. (2017) Fibril structure of amyloid-beta(1-42) by cryo-electron microscopy, Science. 358, 116-119.

132. Kollmer, M., Close, W., Funk, L., Rasmussen, J., Bsoul, A., Schierhorn, A., Schmidt, M., Sigurdson, C. J., Jucker, M. \& Fändrich, M. (2019) Cryo-EM structure and polymorphism of A $\beta$ amyloid fibrils purified from Alzheimer's brain tissue, Nature Communications. 10, 4760.

133. Roder, C., Kupreichyk, T., Gremer, L., Schafer, L. U., Pothula, K. R., Ravelli, R. B. G., Willbold, D., Hoyer, W. \& Schroder, G. F. (2020) Cryo-EM structure of islet amyloid polypeptide fibrils reveals similarities with amyloid-beta fibrils, Nat Struct Mol Biol. 27, 660-667.

134. Liberta, F., Loerch, S., Rennegarbe, M., Schierhorn, A., Westermark, P., Westermark, G. T., Hazenberg, B. P. C., Grigorieff, N., Fandrich, M. \& Schmidt, M. (2019) Cryo-EM fibril structures from systemic AA amyloidosis reveal the species complementarity of pathological amyloids, Nat Commun. 10, 1104.

135. Wasmer, C., Zimmer, A., Sabate, R., Soragni, A., Saupe, S. J., Ritter, C. \& Meier, B. H. (2010) Structural similarity between the prion domain of HET-s and a homologue can explain amyloid crossseeding in spite of limited sequence identity, Journal of molecular biology. 402, 311-25.

136. Benkemoun, L., Ness, F., Sabate, R., Ceschin, J., Breton, A., Clave, C. \& Saupe, S. J. (2011) Two structurally similar fungal prions efficiently cross-seed in vivo but form distinct polymers when coexpressed, Mol Microbiol. 82, 1392-405.

137. Fernandez-Escamilla, A. M., Rousseau, F., Schymkowitz, J. \& Serrano, L. (2004) Prediction of sequence-dependent and mutational effects on the aggregation of peptides and proteins, Nature Biotechnology. 22, 1302-1306.

138. Rousseau, F., Serrano, L. \& Schymkowitz, J. W. (2006) How evolutionary pressure against protein aggregation shaped chaperone specificity, J Mol Biol. 355, 1037-47.

139. Goldschmidt, L., Teng, P. K., Riek, R. \& Eisenberg, D. (2010) Identifying the amylome, proteins capable of forming amyloid-like fibrils, Proceedings of the National Academy of Sciences of the United States of America. 107, 3487-3492.

140. Louros, N., Konstantoulea, K., De Vleeschouwer, M., Ramakers, M., Schymkowitz, J. \& Rousseau, F. (2020) WALTZ-DB 2.0: an updated database containing structural information of experimentally determined amyloid-forming peptides, Nucleic Acids Res. 48, D389-D393.

141. Louros, N., Orlando, G., De Vleeschouwer, M., Rousseau, F. \& Schymkowitz, J. (2020) Structurebased machine-guided mapping of amyloid sequence space reveals uncharted sequence clusters with higher solubilities, Nature communications. 11, 3314.

142. Iadanza, M. G., Jackson, M. P., Hewitt, E. W., Ranson, N. A. \& Radford, S. E. (2018) A new era for understanding amyloid structures and disease, Nat Rev Mol Cell Biol. 19, 755-773.

143. Nelson, R., Sawaya, M. R., Balbirnie, M., Madsen, A. O., Riekel, C., Grothe, R. \& Eisenberg, D. (2005) Structure of the cross-beta spine of amyloid-like fibrils, Nature. 435, 773-8.

144. Sawaya, M. R., Sambashivan, S., Nelson, R., Ivanova, M. I., Sievers, S. A., Apostol, M. I., Thompson, M. J., Balbirnie, M., Wiltzius, J. J., McFarlane, H. T., Madsen, A. O., Riekel, C. \& Eisenberg, D. (2007) Atomic structures of amyloid cross-beta spines reveal varied steric zippers, Nature. 447, 4537.

145. Makin, O. S. \& Serpell, L. C. (2005) Structures for amyloid fibrils, FEBS J. 272, 5950-61.

146. Apostol, M. I., Wiltzius, J. J., Sawaya, M. R., Cascio, D. \& Eisenberg, D. (2011) Atomic structures suggest determinants of transmission barriers in mammalian prion disease, Biochemistry. 50, 2456-63. 147. Louros, N. N., Tsiolaki, P. L., Zompra, A. A., Pappa, E. V., Magafa, V., Pairas, G., Cordopatis, P., Cheimonidou, C., Trougakos, I. P., Iconomidou, V. A. \& Hamodrakas, S. J. (2015) Structural studies and cytotoxicity assays of "aggregation-prone" IAPP(8-16) and its non-amyloidogenic variants suggest its important role in fibrillogenesis and cytotoxicity of human amylin, Biopolymers. 104, 196-205.

148. Louros, N. N., Tsiolaki, P. L., Baltoumas, F. A., Chryssikos, G. D., Gionis, V., Hamodrakas, S. J. \& Iconomidou, V. A. (2017) Tracking the amyloidogenic core of IAPP amyloid fibrils: Insights from microRaman spectroscopy, J Struct Biol. 199, 140-152.

149. Marshall, K. E., Vadukul, D. M., Dahal, L., Theisen, A., Fowler, M. W., Al-Hilaly, Y., Ford, L., Kemenes, G., Day, I. J., Staras, K. \& Serpell, L. C. (2016) A critical role for the self-assembly of Amyloidbeta1-42 in neurodegeneration, Sci Rep. 6, 30182.

150. Ganesan, A., Siekierska, A., Beerten, J., Brams, M., Van Durme, J., De Baets, G., Van der Kant, R., Gallardo, R., Ramakers, M., Langenberg, T., Wilkinson, H., De Smet, F., Ulens, C., Rousseau, F. \& 
Schymkowitz, J. (2016) Structural hot spots for the solubility of globular proteins, Nature communications. 7, 10816.

151. Morell, M., Bravo, R., Espargaro, A., Sisquella, X., Aviles, F. X., Fernandez-Busquets, X. \& Ventura, S. (2008) Inclusion bodies: specificity in their aggregation process and amyloid-like structure, Biochim Biophys Acta. 1783, 1815-25.

152. Colletier, J. P., Laganowsky, A., Landau, M., Zhao, M., Soriaga, A. B., Goldschmidt, L., Flot, D., Cascio, D., Sawaya, M. R. \& Eisenberg, D. (2011) Molecular basis for amyloid-beta polymorphism, Proc Natl Acad Sci U S A. 108, 16938-43.

153. Kajava, A. V., Aebi, U. \& Steven, A. C. (2005) The parallel superpleated beta-structure as a model for amyloid fibrils of human amylin, Journal of molecular biology. 348, 247-52.

154. Kajava, A. V., Baxa, U., Wickner, R. B. \& Steven, A. C. (2004) A model for Ure2p prion filaments and other amyloids: the parallel superpleated beta-structure, Proc Natl Acad Sci U S A. 101, 7885-90. 155. Park, J., Kahng, B. \& Hwang, W. (2009) Thermodynamic selection of steric zipper patterns in the amyloid cross-beta spine, PLoS Comput Biol. 5, e1000492.

156. Schmidt, M., Wiese, S., Adak, V., Engler, J., Agarwal, S., Fritz, G., Westermark, P., Zacharias, M. \& Fandrich, M. (2019) Cryo-EM structure of a transthyretin-derived amyloid fibril from a patient with hereditary ATTR amyloidosis, Nat Commun. 10, 5008.

157. Swuec, P., Lavatelli, F., Tasaki, M., Paissoni, C., Rognoni, P., Maritan, M., Brambilla, F., Milani, P., Mauri, P., Camilloni, C., Palladini, G., Merlini, G., Ricagno, S. \& Bolognesi, M. (2019) Cryo-EM structure of cardiac amyloid fibrils from an immunoglobulin light chain $\mathrm{AL}$ amyloidosis patient, Nat Commun. 10, 1269.

158. Iadanza, M. G., Silvers, R., Boardman, J., Smith, H. I., Karamanos, T. K., Debelouchina, G. T., Su, Y., Griffin, R. G., Ranson, N. A. \& Radford, S. E. (2018) The structure of a beta2-microglobulin fibril suggests a molecular basis for its amyloid polymorphism, Nat Commun. 9, 4517.

159. Cao, Q., Boyer, D. R., Sawaya, M. R., Ge, P. \& Eisenberg, D. S. (2019) Cryo-EM structures of four polymorphic TDP-43 amyloid cores, Nat Struct Mol Biol. 26, 619-627.

160. Fitzpatrick, A. W. P., Falcon, B., He, S., Murzin, A. G., Murshudov, G., Garringer, H. J., Crowther, R. A., Ghetti, B., Goedert, M. \& Scheres, S. H. W. (2017) Cryo-EM structures of tau filaments from Alzheimer's disease, Nature. 547, 185-190.

161. Griner, S. L., Seidler, P., Bowler, J., Murray, K. A., Yang, T. P., Sahay, S., Sawaya, M. R., Cascio, D., Rodriguez, J. A., Philipp, S., Sosna, J., Glabe, C. G., Gonen, T. \& Eisenberg, D. S. (2019) Structurebased inhibitors of amyloid beta core suggest a common interface with tau, Elife. $\mathbf{8}$.

162. Seidler, P. M., Boyer, D. R., Rodriguez, J. A., Sawaya, M. R., Cascio, D., Murray, K., Gonen, T. \& Eisenberg, D. S. (2018) Structure-based inhibitors of tau aggregation, Nat Chem. 10, 170-176.

163. Beerten, J., Jonckheere, W., Rudyak, S., Xu, J., Wilkinson, H., De Smet, F., Schymkowitz, J. \& Rousseau, F. (2012) Aggregation gatekeepers modulate protein homeostasis of aggregating sequences and affect bacterial fitness, Protein Eng Des Sel. 25, 357-66.

164. Beerten, J., Schymkowitz, J. \& Rousseau, F. (2012) Aggregation prone regions and gatekeeping residues in protein sequences, Curr Top Med Chem. 12, 2470-8.

165. Houben, B., Michiels, E., Ramakers, M., Konstantoulea, K., Louros, N., Verniers, J., van der Kant, R., De Vleeschouwer, M., Chicoria, N., Vanpoucke, T., Gallardo, R., Schymkowitz, J. \& Rousseau, F. (2020) Autonomous aggregation suppression by acidic residues explains why chaperones favour basic residues, EMBO J. 39, e102864.

166. Langenberg, T., Gallardo, R., van der Kant, R., Louros, N., Michiels, E., Duran-Romana, R., Houben, B., Cassio, R., Wilkinson, H., Garcia, T., Ulens, C., Van Durme, J., Rousseau, F. \& Schymkowitz, J. (2020) Thermodynamic and Evolutionary Coupling between the Native and Amyloid State of Globular Proteins, Cell reports. 31, 107512.

167. Michiels, E., Liu, S., Gallardo, R., Louros, N., Mathelie-Guinlet, M., Dufrene, Y., Schymkowitz, J., Vorberg, I. \& Rousseau, F. (2020) Entropic Bristles Tune the Seeding Efficiency of Prion-Nucleating Fragments, Cell reports. 30, 2834-2845 e3.

168. Mompean, M., Li, W., Li, J., Laage, S., Siemer, A. B., Bozkurt, G., Wu, H. \& McDermott, A. E. (2018) The Structure of the Necrosome RIPK1-RIPK3 Core, a Human Hetero-Amyloid Signaling Complex, Cell. 173, 1244-1253 e10.

169. Grizel, A. V., Rubel, A. A. \& Chernoff, Y. O. (2016) Strain conformation controls the specificity of cross-species prion transmission in the yeast model, Prion. 10, 269-82.

170. Baskakov, I. V. (2009) Switching in amyloid structure within individual fibrils: implication for strain adaptation, species barrier and strain classification, FEBS Lett. 583, 2618-22.

171. Do, T. D., Sangwan, S., de Almeida, N. E. C., Ilitchev, A. I., Giammona, M., Sawaya, M. R., Buratto, S. K., Eisenberg, D. S. \& Bowers, M. T. (2018) Distal amyloid beta-protein fragments template amyloid assembly, Protein Sci. 27, 1181-1190. 
172. Yan, L.-M., Velkova, A., Tatarek-Nossol, M., Andreetto, E. \& Kapurniotu, A. (2007) IAPP mimic blocks Abeta cytotoxic self-assembly: cross-suppression of amyloid toxicity of Abeta and IAPP suggests a molecular link between Alzheimer's disease and type II diabetes, Angewandte Chemie (International ed in English). 46, 1246-1252.

173. Wang, Y. \& Hall, C. K. (2018) Seeding and cross-seeding fibrillation of N-terminal prion protein peptides PrP(120-144), Protein Sci. 27, 1304-1313.

174. Krotee, P., Griner, S. L., Sawaya, M. R., Cascio, D., Rodriguez, J. A., Shi, D., Philipp, S., Murray, K., Saelices, L., Lee, J., Seidler, P., Glabe, C. G., Jiang, L., Gonen, T. \& Eisenberg, D. S. (2018) Common fibrillar spines of amyloid-beta and human islet amyloid polypeptide revealed by microelectron diffraction and structure-based inhibitors, J Biol Chem. 293, 2888-2902.

175. Baram, M., Atsmon-Raz, Y., Ma, B., Nussinov, R. \& Miller, Y. (2016) Amylin-Abeta oligomers at atomic resolution using molecular dynamics simulations: a link between Type 2 diabetes and Alzheimer's disease, Phys Chem Chem Phys. 18, 2330-8.

176. Zhou, Y., Smith, D., Leong, B. J., Brannstrom, K., Almqvist, F. \& Chapman, M. R. (2012) Promiscuous cross-seeding between bacterial amyloids promotes interspecies biofilms, J Biol Chem. 287, 35092-103.

177. Louros, N. N., Chrysina, E. D., Baltatzis, G. E., Patsouris, E. S., Hamodrakas, S. J. \& Iconomidou, V. A. (2016) A common 'aggregation-prone' interface possibly participates in the self-assembly of human zona pellucida proteins, FEBS Lett. 590, 619-30.

178. Louros, N. N., Bolas, G. M. P., Tsiolaki, P. L., Hamodrakas, S. J. \& Iconomidou, V. A. (2016) Intrinsic aggregation propensity of the CsgB nucleator protein is crucial for curli fiber formation, $J$ Struct Biol. 195, 179-189.

179. Louros, N. N., Iconomidou, V. A., Giannelou, P. \& Hamodrakas, S. J. (2013) Structural analysis of peptide-analogues of human Zona Pellucida ZP1 protein with amyloidogenic properties: insights into mammalian Zona Pellucida formation, PLoS One. 8, e73258.

180. Louros, N. N., Petronikolou, N., Karamanos, T., Cordopatis, P., Iconomidou, V. A. \& Hamodrakas, S. J. (2014) Structural studies of "aggregation-prone" peptide-analogues of teleostean egg chorion ZPB proteins, Biopolymers. 102, 427-36.

181. Tsiolaki, P. L., Louros, N. N. \& Iconomidou, V. A. (2018) Hexapeptide Tandem Repeats Dictate the Formation of Silkmoth Chorion, a Natural Protective Amyloid, Journal of molecular biology. 430, 3774-3783.

182. Do, H. Q., Hewetson, A., Myers, C., Khan, N. H., Hastert, M. C., F, M. H., Latham, M. P., Wylie, B. J., Sutton, R. B. \& Cornwall, G. A. (2019) The Functional Mammalian CRES (Cystatin-Related Epididymal Spermatogenic) Amyloid is Antiparallel beta-Sheet Rich and Forms a Metastable Oligomer During Assembly, Sci Rep. 9, 9210.

183. Xu, J., Reumers, J., Couceiro, J. R., De Smet, F., Gallardo, R., Rudyak, S., Cornelis, A., Rozenski, J., Zwolinska, A., Marine, J. C., Lambrechts, D., Suh, Y. A., Rousseau, F. \& Schymkowitz, J. (2011) Gain of function of mutant p53 by coaggregation with multiple tumor suppressors, Nat Chem Biol. 7 , 285-95.

184. Russo, C., Osterburg, C., Sirico, A., Antonini, D., Ambrosio, R., Wurz, J. M., Rinnenthal, J., Ferniani, M., Kehrloesser, S., Schafer, B., Guntert, P., Sinha, S., Dotsch, V. \& Missero, C. (2018) Protein aggregation of the p63 transcription factor underlies severe skin fragility in AEC syndrome, Proc Natl Acad Sci U S A. 115, E906-E915.

185. Kehrloesser, S., Osterburg, C., Tuppi, M., Schafer, B., Vousden, K. H. \& Dotsch, V. (2016) Intrinsic aggregation propensity of the p63 and p73 $\mathrm{TI}$ domains correlates with p53R175H interaction and suggests further significance of aggregation events in the p53 family, Cell death and differentiation. 23, 1952-1960.

186. Barnhart, M. M. \& Chapman, M. R. (2006) Curli biogenesis and function, Annu Rev Microbiol. 60, 131-47.

187. Bhoite, S., van Gerven, N., Chapman, M. R. \& Remaut, H. (2019) Curli Biogenesis: Bacterial Amyloid Assembly by the Type VIII Secretion Pathway, EcoSal Plus. 8.

188. Evans, M. L. \& Chapman, M. R. (2014) Curli biogenesis: order out of disorder, Biochim Biophys Acta. 1843, 1551-8.

189. Hammer, N. D., Schmidt, J. C. \& Chapman, M. R. (2007) The curli nucleator protein, CsgB, contains an amyloidogenic domain that directs CsgA polymerization, Proc Natl Acad Sci U S A. 104, 12494-9.

190. Shu, Q., Crick, S. L., Pinkner, J. S., Ford, B., Hultgren, S. J. \& Frieden, C. (2012) The E. coli CsgB nucleator of curli assembles to beta-sheet oligomers that alter the CsgA fibrillization mechanism, Proc Natl Acad Sci U S A. 109, 6502-7. 
191. Hammar, M., Bian, Z. \& Normark, S. (1996) Nucleator-dependent intercellular assembly of adhesive curli organelles in Escherichia coli, Proc Natl Acad Sci U S A. 93, 6562-6.

192. Collinson, S. K., Parker, J. M., Hodges, R. S. \& Kay, W. W. (1999) Structural predictions of AgfA, the insoluble fimbrial subunit of Salmonella thin aggregative fimbriae, Journal of molecular biology. 290, 741-56.

193. White, A. P., Collinson, S. K., Banser, P. A., Gibson, D. L., Paetzel, M., Strynadka, N. C. \& Kay, W. W. (2001) Structure and characterization of AgfB from Salmonella enteritidis thin aggregative fimbriae, Journal of molecular biology. 311, 735-49.

194. Andreasen, M., Meisl, G., Taylor, J. D., Michaels, T. C. T., Levin, A., Otzen, D. E., Chapman, M. R., Dobson, C. M., Matthews, S. J. \& Knowles, T. P. J. (2019) Physical Determinants of Amyloid Assembly in Biofilm Formation, mBio. 10.

195. Dueholm, M. S., Sondergaard, M. T., Nilsson, M., Christiansen, G., Stensballe, A., Overgaard, M. T., Givskov, M., Tolker-Nielsen, T., Otzen, D. E. \& Nielsen, P. H. (2013) Expression of Fap amyloids in Pseudomonas aeruginosa, P. fluorescens, and P. putida results in aggregation and increased biofilm formation, Microbiologyopen. 2, 365-82.

196. Claessen, D., Rink, R., de Jong, W., Siebring, J., de Vreugd, P., Boersma, F. G., Dijkhuizen, L. \& Wosten, H. A. (2003) A novel class of secreted hydrophobic proteins is involved in aerial hyphae formation in Streptomyces coelicolor by forming amyloid-like fibrils, Genes Dev. 17, 1714-26.

197. Hewetson, A., Do, H. Q., Myers, C., Muthusubramanian, A., Sutton, R. B., Wylie, B. J. \& Cornwall, G. A. (2017) Functional Amyloids in Reproduction, Biomolecules. 7.

198. Iconomidou, V. A., Vriend, G. \& Hamodrakas, S. J. (2000) Amyloids protect the silkmoth oocyte and embryo, FEBS Lett. 479, 141-5.

199. Podrabsky, J. E., Carpenter, J. F. \& Hand, S. C. (2001) Survival of water stress in annual fish embryos: dehydration avoidance and egg envelope amyloid fibers, Am J Physiol Regul Integr Comp Physiol. 280, R123-31.

200. Iconomidou, V. A., Chryssikos, G. D., Gionis, V., Galanis, A. S., Cordopatis, P., Hoenger, A. \& Hamodrakas, S. J. (2006) Amyloid fibril formation propensity is inherent into the hexapeptide tandemly repeating sequence of the central domain of silkmoth chorion proteins of the A-family, J Struct Biol. $156,480-8$.

201. Iconomidou, V. A., Chryssikos, G. D., Gionis, V., Vriend, G., Hoenger, A. \& Hamodrakas, S. J. (2001) Amyloid-like fibrils from an 18-residue peptide analogue of a part of the central domain of the Bfamily of silkmoth chorion proteins, FEBS Lett. 499, 268-73.

202. Litscher, E. S. \& Wassarman, P. M. (2007) Egg extracellular coat proteins: from fish to mammals, Histol Histopathol. 22, 337-47.

203. Egge, N., Muthusubramanian, A. \& Cornwall, G. A. (2015) Amyloid properties of the mouse egg zona pellucida, PLoS One. 10, e0129907.

204. Guyonnet, B., Egge, N. \& Cornwall, G. A. (2014) Functional amyloids in the mouse sperm acrosome, Mol Cell Biol. 34, 2624-34.

205. Easterhoff, D., Ontiveros, F., Brooks, L. R., Kim, Y., Ross, B., Silva, J. N., Olsen, J. S., Feng, C., Hardy, D. J., Dunman, P. M. \& Dewhurst, S. (2013) Semen-derived enhancer of viral infection (SEVI) binds bacteria, enhances bacterial phagocytosis by macrophages, and can protect against vaginal infection by a sexually transmitted bacterial pathogen, Antimicrob Agents Chemother. 57, 2443-50.

206. Roan, N. R., Sandi-Monroy, N., Kohgadai, N., Usmani, S. M., Hamil, K. G., Neidleman, J., Montano, M., Standker, L., Rocker, A., Cavrois, M., Rosen, J., Marson, K., Smith, J. F., Pilcher, C. D., Gagsteiger, F., Sakk, O., O'Rand, M., Lishko, P. V., Kirchhoff, F., Munch, J. \& Greene, W. C. (2017) Semen amyloids participate in spermatozoa selection and clearance, Elife. $\mathbf{6}$.

207. Munch, J., Rucker, E., Standker, L., Adermann, K., Goffinet, C., Schindler, M., Wildum, S., Chinnadurai, R., Rajan, D., Specht, A., Gimenez-Gallego, G., Sanchez, P. C., Fowler, D. M., Koulov, A., Kelly, J. W., Mothes, W., Grivel, J. C., Margolis, L., Keppler, O. T., Forssmann, W. G. \& Kirchhoff, F. (2007) Semen-derived amyloid fibrils drastically enhance HIV infection, Cell. 131, 1059-71.

208. Wojtowicz, W. M., Farzan, M., Joyal, J. L., Carter, K., Babcock, G. J., Israel, D. I., Sodroski, J. \& Mirzabekov, T. (2002) Stimulation of enveloped virus infection by beta-amyloid fibrils, J Biol Chem. 277, 35019-24.

209. Ezzat, K., Pernemalm, M., Palsson, S., Roberts, T. C., Jarver, P., Dondalska, A., Bestas, B., Sobkowiak, M. J., Levanen, B., Skold, M., Thompson, E. A., Saher, O., Kari, O. K., Lajunen, T., Sverremark Ekstrom, E., Nilsson, C., Ishchenko, Y., Malm, T., Wood, M. J. A., Power, U. F., Masich, S., Linden, A., Sandberg, J. K., Lehtio, J., Spetz, A. L. \& El Andaloussi, S. (2019) The viral protein corona directs viral pathogenesis and amyloid aggregation, Nat Commun. 10, 2331. 
210. Tan, S., Li, L., Lu, L., Pan, C., Lu, H., Oksov, Y., Tang, X., Jiang, S. \& Liu, S. (2014) Peptides derived from HIV-1 gp120 co-receptor binding domain form amyloid fibrils and enhance HIV-1 infection, FEBS Lett. 588, 1515-22.

211. Zheng, X., Jia, L., Hu, B., Sun, Y., Zhang, Y., Gao, X., Deng, T., Bao, S., Xu, L. \& Zhou, J. (2015) The C-terminal amyloidogenic peptide contributes to self-assembly of Avibirnavirus viral protease, Sci Rep. 5, 14794.

212. Li, J., McQuade, T., Siemer, A. B., Napetschnig, J., Moriwaki, K., Hsiao, Y. S., Damko, E., Moquin, D., Walz, T., McDermott, A., Chan, F. K. \& Wu, H. (2012) The RIP1/RIP3 necrosome forms a functional amyloid signaling complex required for programmed necrosis, Cell. 150, 339-50.

213. Wu, X. N., Yang, Z. H., Wang, X. K., Zhang, Y., Wan, H., Song, Y., Chen, X., Shao, J. \& Han, J. (2014) Distinct roles of RIP1-RIP3 hetero- and RIP3-RIP3 homo-interaction in mediating necroptosis, Cell Death Differ. 21, 1709-20.

214. Liu, S., Liu, H., Johnston, A., Hanna-Addams, S., Reynoso, E., Xiang, Y. \& Wang, Z. (2017) MLKL forms disulfide bond-dependent amyloid-like polymers to induce necroptosis, Proc Natl Acad Sci U S A. 114, E7450-E7459.

215. Petrie, E. J., Sandow, J. J., Lehmann, W. I. L., Liang, L. Y., Coursier, D., Young, S. N., Kersten, W. J. A., Fitzgibbon, C., Samson, A. L., Jacobsen, A. V., Lowes, K. N., Au, A. E., Jousset Sabroux, H., Lalaoui, N., Webb, A. I., Lessene, G., Manning, G., Lucet, I. S. \& Murphy, J. M. (2019) Viral MLKL Homologs Subvert Necroptotic Cell Death by Sequestering Cellular RIPK3, Cell Rep. 28, 3309-3319 e5.

216. Pham, C. L., Shanmugam, N., Strange, M., O'Carroll, A., Brown, J. W., Sierecki, E., Gambin, Y., Steain, M. \& Sunde, M. (2019) Viral M45 and necroptosis-associated proteins form heteromeric amyloid assemblies, EMBO Rep. 20.

217. Bondarev, S. A., Antonets, K. S., Kajava, A. V., Nizhnikov, A. A. \& Zhouravleva, G. A. (2018) Protein Co-Aggregation Related to Amyloids: Methods of Investigation, Diversity, and Classification, Int J Mol Sci. 19.

218. Kajava, A. V., Klopffleisch, K., Chen, S. \& Hofmann, K. (2014) Evolutionary link between metazoan RHIM motif and prion-forming domain of fungal heterokaryon incompatibility factor HET-s/HET-s, Sci Rep. 4, 7436.

219. Loquet, A. \& Saupe, S. J. (2017) Diversity of Amyloid Motifs in NLR Signaling in Fungi, Biomolecules. 7.

220. Kleino, A., Ramia, N. F., Bozkurt, G., Shen, Y., Nailwal, H., Huang, J., Napetschnig, J., Gangloff, M., Chan, F. K., Wu, H., Li, J. \& Silverman, N. (2017) Peptidoglycan-Sensing Receptors Trigger the Formation of Functional Amyloids of the Adaptor Protein Imd to Initiate Drosophila NF-kappaB Signaling, Immunity. 47, 635-647 e6.

221. Vishveshwara, N. \& Liebman, S. W. (2009) Heterologous cross-seeding mimics cross-species prion conversion in a yeast model, BMC Biol. 7, 26.

222. Luers, L., Bannach, O., Stohr, J., Wordehoff, M. M., Wolff, M., Nagel-Steger, L., Riesner, D., Willbold, D. \& Birkmann, E. (2013) Seeded fibrillation as molecular basis of the species barrier in human prion diseases, PLoS One. 8, e72623.

223. Li, X., Rayman, J. B., Kandel, E. R. \& Derkatch, I. L. (2014) Functional role of Tia1/Pub1 and Sup35 prion domains: directing protein synthesis machinery to the tubulin cytoskeleton, Mol Cell. 55, 305-18.

224. Keefer, K. M., Stein, K. C. \& True, H. L. (2017) Heterologous prion-forming proteins interact to cross-seed aggregation in Saccharomyces cerevisiae, Sci Rep. 7, 5853.

225. Shida, T., Kamatari, Y. O., Yoda, T., Yamaguchi, Y., Feig, M., Ohhashi, Y., Sugita, Y., Kuwata, K. \& Tanaka, M. (2020) Short disordered protein segment regulates cross-species transmission of a yeast prion, Nat Chem Biol. 16, 756-765.

226. Jones, E. M. \& Surewicz, W. K. (2005) Fibril conformation as the basis of species- and straindependent seeding specificity of mammalian prion amyloids, Cell. 121, 63-72.

227. Makarava, N. \& Baskakov, I. V. (2012) Genesis of tramsmissible protein states via deformed templating, Prion. 6, 252-5.

228. Dean, D. N. \& Lee, J. C. (2020) Modulating functional amyloid formation via alternative splicing of the premelanosomal protein PMEL17, J Biol Chem. 295, 7544-7553.

229. Nespovitaya, N., Mahou, P., Laine, R. F., Schierle, G. S. K. \& Kaminski, C. F. (2017) Heparin acts as a structural component of beta-endorphin amyloid fibrils rather than a simple aggregation promoter, Chem Commun (Camb). 53, 1273-1276.

230. Ayyadevara, S., Balasubramaniam, M., Parcon, P. A., Barger, S. W., Griffin, W. S., Alla, R., Tackett, A. J., Mackintosh, S. G., Petricoin, E., Zhou, W. \& Shmookler Reis, R. J. (2016) Proteins that 
mediate protein aggregation and cytotoxicity distinguish Alzheimer's hippocampus from normal controls, Aging Cell. 15, 924-39.

231. Chai, Y. H., Shao, J. Q., Miller, V. M., Williams, A. \& Paulson, H. L. (2002) Live-cell imaging reveals divergent intracellular dynamics of polyglutamine disease proteins and supports a sequestration model of pathogenesis, $P$ Natl Acad Sci USA. 99, 9310-9315.

232. Montalbano, M., McAllen, S., Puangmalai, N., Sengupta, U., Bhatt, N., Johnson, O. D., Kharas, M. G. \& Kayed, R. (2020) RNA-binding proteins Musashi and tau soluble aggregates initiate nuclear dysfunction, Nat Commun. 11, 4305.

233. Wingo, A. P., Fan, W., Duong, D. M., Gerasimov, E. S., Dammer, E. B., Liu, Y., Harerimana, N. V., White, B., Thambisetty, M., Troncoso, J. C., Kim, N., Schneider, J. A., Hajjar, I. M., Lah, J. J., Bennett, D. A., Seyfried, N. T., Levey, A. I. \& Wingo, T. S. (2020) Shared proteomic effects of cerebral atherosclerosis and Alzheimer's disease on the human brain, Nat Neurosci. 23, 696-700.

234. Chen, W. T., Lu, A., Craessaerts, K., Pavie, B., Sala Frigerio, C., Corthout, N., Qian, X., Lalakova, J., Kuhnemund, M., Voytyuk, I., Wolfs, L., Mancuso, R., Salta, E., Balusu, S., Snellinx, A., Munck, S., Jurek, A., Fernandez Navarro, J., Saido, T. C., Huitinga, I., Lundeberg, J., Fiers, M. \& De Strooper, B. (2020) Spatial Transcriptomics and In Situ Sequencing to Study Alzheimer's Disease, Cell. 182, 976991 e19.

235. Andreetto, E., Yan, L. M., Tatarek-Nossol, M., Velkova, A., Frank, R. \& Kapurniotu, A. (2010) Identification of hot regions of the Abeta-IAPP interaction interface as high-affinity binding sites in both cross- and self-association, Angew Chem Int Ed Engl. 49, 3081-5.

236. Tsai, Y. C., Fishman, P. S., Thakor, N. V. \& Oyler, G. A. (2003) Parkin facilitates the elimination of expanded polyglutamine proteins and leads to preservation of proteasome function, $\mathrm{J}$ Biol Chem. 278, 22044-55.

237. Janer, A., Werner, A., Takahashi-Fujigasaki, J., Daret, A., Fujigasaki, H., Takada, K., Duyckaerts, C., Brice, A., Dejean, A. \& Sittler, A. (2010) SUMOylation attenuates the aggregation propensity and cellular toxicity of the polyglutamine expanded ataxin-7, Hum Mol Genet. 19, 181-95.

238. Guerreiro, P. S., Huang, Y., Gysbers, A., Cheng, D., Gai, W. P., Outeiro, T. F. \& Halliday, G. M. (2013) LRRK2 interactions with alpha-synuclein in Parkinson's disease brains and in cell models, J Mol Med (Berl). 91, 513-22.

239. Magalhaes, J. \& Saraiva, M. J. (2011) Clusterin overexpression and its possible protective role in transthyretin deposition in familial amyloidotic polyneuropathy, J Neuropathol Exp Neurol. 70, 1097106.

240. Oskarsson, M. E., Hermansson, E., Wang, Y., Welsh, N., Presto, J., Johansson, J. \& Westermark, G. T. (2018) BRICHOS domain of Bri2 inhibits islet amyloid polypeptide (IAPP) fibril formation and toxicity in human beta cells, Proc Natl Acad Sci U S A. 115, E2752-E2761. 
Table 1. Definitions of terms used throughout the text.

Proteinopathies: Pathologies associated with protein aggregation and deposition which is promoted by selfassembly of amyloidogenic proteins.

Heterotypic interactions: Any type of transient or permanent physical interaction between protein molecules with different primary structures.

Cross-seeding: Also defined as heterologous seeding, this process describes the ability of pre-formed seeds to promote the nucleation of a different protein. This can refer to species-related homologous sequences, disease variants or completely different protein sequences.

Co-aggregation: The heterogeneous condition of protein coassembly once different proteins are dissolved in pairwise mixtures. Differs from cross-seeding in the sense that there is an absence of pre-formed seeds that can promote nucleation of either protein component.

Cellular selective vulnerability: The process in which only particular cell-types are pathologically affected by the presence of protein aggregates.

Supersaturated proteins: Subcellular accumulation of specific subproteomic populations to levels beyond their intrinsic solubility. This process can potentially promote additional protein components to collapse into aggregate deposits through heterotypic interactions.

Biomolecular condensation: Formation of membrane-less cellular inclusions by concentrated biomolecules. Their formation occurs through reversible phase transition.
Heterotypic buffering: Biomolecular crowding effect induced by heterotypic interactions that reduce pathological homotypic aggregation and condensation.

Phase transition: The process of abruptly changing the physical properties of a state of matter by cooperative local overcrowding of biomolecules.

Phase separation: Physical separation of locally coexisting phases produced by phase transition. This involves the separation of liquid phases with different densities (liquid-liquid phase separation - LLPS) or liquid-to solid-phase separation.

Prion transmissibility: The ability of infectious protein aggregates to spread between different tissues/organs and further promote aggregation. Cross-species prion infectivity is determined through barriers defined by sequence specificity and structural compatibility.

Aggregation prone regions: Short sequence stretches with a strong tendency to form amyloid-like aggregates through homotypic assembly.

Amyloid polymorphism/strains. The ability of amyloidogenic proteins to form amyloid fibrils of variable distinct structural morphologies that can potentially contribute differentially to disease or transmissibility.

Functional amyloids: Amyloid fibril formation that supports important biological functions in organisms spanning from humans to bacteria. 


\section{Figure Legends}

Figure 1. Dense cross-talk of amyloidogenic proteins and their relation to proteinopathies. Primary amyloidogenic components (red rhomboid nodes) of several major amyloidosis diseases affecting a variety of tissues and organs have been shown to engage in heterotypic interplay (solid gray lines) and are occasionally found as secondary components in deposits (dashed grey lines) [16-18, 28, 29, 32-34, 42-46, 50, 235].

Figure 2. Co-localization of disease-associated protein aggregates with additional cellular components. Co-localization of secernin-1 with $A \beta$ in SAD human brains [54], filamin-1 with Tau in NFTs from FTDP-17 [55], parkin and Huntingtin in human HD brains [236], sumo2 and ataxin-7 in human SCA7 brains [237], LRRK2 and $\alpha$-synuclein in PD brains [238], clusterin and TTR in FAP [239] and proximity ligation assay of Bri2 and IAPP in T2D [240]. Figures were adapted with permission from [54, 55, 236-240].

Figure 3. Heterotypic interactions contribute to the proteostatic equilibrium of protein aggregation-induced toxicity. Hetero-aggregation can promote the entrapment of proteins through phase transition events, by depleting selectively vulnerable proteins, by targeting supersaturated populations or as a combination of the above. In contrast, cellular proteostatic mechanisms and heteromolecular crowding has been suggested to work in parallel as protective mechanisms providing resistance to toxic effects of aggregation. 